\title{
ESTUDIO DEL RITMO DE VIDA EN UNA PEQUEÑA COMUNIDAD URBANA
}

Por MARIA ROSA MALLOL DE RECASENS 


\section{INTRODUCCION}

El presente estudio forma parte del análisis global para la comunidad de Puerto Colombia. Constituye uno de los capítulos de importancia para el enfoque de la vida de esta pequeña comunidad urbana, que se halla en la fase de estabilización, después del cambio producido por el abandono de lo que fue su puerto, hoy traspasado al Terminal Marítimo de Barranquilla.

El Municipio de Puerto Colombia está situado en la costa atlántica, a 25 kilómetros al oeste de Barranquilla, en el Departamento del Atlántico; tiene una población total de 8.172, según el censo de 1951, que puede considerarse creciente ya que el censo del año 1938 fue de 7.151 habitantes.

Su clima corresponde al del piso térmico cálido, con un microclima litoral cuyas características son las siguientes: temperatura media anual, $28.2^{\circ}$ C., según medición en el período de 1937-1946, con una época de brisa (vientos alisios) durante los meses de noviembre a marzo. La lluviosidad media es de $\mathbf{5 4 0 . 7}$ $\mathrm{mm}$.; el período lluvioso corresponde a los meses de abril a noviembre. Las condiciones generales de Puerto Colombia corresponden a la tipología de clima de la Costa Atlántica, y su microclima a las condiciones de la desembocadura del río Magdalena.

Las razones para escoger este núcleo fueron muchas, pero las principales se originaron en nuestro conocimiento personal, año tras año, de los cambios ocurridos desde que se cerró a la navegación el puerto marítimo. En el pasado representó un núcleo urbano relativamente independiente de Barranquilla. La vida del puerto marítimo era suficientemente importante para que el Municipio tuviera una existencia autónoma; al cerrarse su puerto cambiaron radicalmente las condiciones y pasó a ser un centro dependiente de Barranquilla. Siendo la playa más cer- 
cana, comenzaron a construírse casas de veraneo para las familias barranquilleras y aun surgió como centro turístico que atraía gentes de otros Departamentos, para lo que se construyeron y habilitaron numerosos hoteles.

A partir de 1947 ciertos factores geodinámicos modificaron la estructura de la playa, creándose una bahía cerrada de aguas quietas; así, el carácter de región para balnearios lujosos hasta hace 10 años, fue perdiéndose y pasó últimamente a la categoría de lugar para recreación popular de las clases obreras y de bajos ingresos de Barranquilla, que viajan casi únicamente en días festivos a Puerto Colombia.

Mientras tanto una población que en la primera época vivía del puerto, fue adaptándose a las nuevas condiciones de turismo, y actualmente se ve limitada a sobrevivir dentro de la situación de cambio con tendencia a formas cerradas y autónomas de la influencia de Barranquilla. Por otra parte, tiende a constituírse como residencia de un buen grupo de obreros que dependen del trabajo marítimo de la capital del Atlántico.

Hasta cierto punto, puede considerarse a Puerto Colombia algo así como una incipiente ciudad satélite de Barranquilla. El factor importante en la residencia de la mayoría de las personas que allí viven está íntimamente relacionado con situaciones de "status". En realidad, el prestigio social que puede ser mantenido es más alto que el que estas mismas gentes alcanzarían al tener que vivir en Barranquilla, y esto afecta práctica. mente a todas las categorías socio-profesionales estudiadas.

Las modificaciones económicas, sociales y culturales, har. actuado principalmente como sistemas de freno del desarrollo: en efecto, pueden observarse actitudes regresivas (feedback), en que los contextos culturales afectan las posibilidades de progreso técnico y tratan por todos los medios de seguir manteniendo el mismo nivel de reacciones individuales y colectivas de la época en que el puerto era la estructura básica de la vida, aferrándose así a un pasado, a pesar de saber que nunca podrá regresarse a él.

En el fondo de nuestro estudio existe el interés de relacionar el progreso técnico y la comunidad. En el presente caso la relativa inercia, tanto al cambio de las estructuras socio-urbanas como a las innovaciones materiales, nos ha dado indicaciones que son importantes para la organización sistemática de futu- 
ros programas de desarrollo social a nivel de pequeñas colectividades con tendencia urbana. Por otra parte, el análisis de los puntos esenciales de la naturaleza y el papel social de la comunidad local en cuanto a sí misma, así como la importancia particular de las estructuras y fuerzas políticas, confluyen a la armonización de las acciones gubernamentales y administrativas y al juego de los resortes psico-políticos en el seno de la comunidad. Estos aspectos constituirán el tema de futuras publicaciones.

Finalmente, queremos consignar nuestro franco agradecimiento a las personas cuya ayuda facilitó nuestro trabajo, en primer lugar a las familias investigadas, que nos suministraron la información básica; asímismo a las autoridades municipales y eclesiásticas, al personal médico del Puesto de Salud y Puesto de Socorro, a la dirección del magisterio y a numerosas personas de la comunidad que nos ayudaron en la comprensión de los fenómenos de la dinámica social de Puerto Colombia.

\section{METODOLOGIA PARA LA INVESTIGACION DEL RITMO DE VIDA DIARIA EN PUERTO COLOMBIA}

Los últimos trabajos del grupo dirigido por Chombart de Lauwe, han establecido métodos de valoración estadística comparada para la medición horaria de la vida rutinaria de una comunidad. Hemos empleado sus direcciones generales a fin de utilizar la eficacia de su aplicación, y el presente análisis representa el capítulo destinado al estudio del ritmo diario de vida en la zona urbana de Puerto Colombia.

Consideramos conveniente describir la metodología empleada. Para la tabulación de la encuesta se usó un círculo dividido en 24 espacios correspondientes a las horas del día. Establecido el muestreo para interrogar a un número de familias proporcialmente representativas de los grupos socio-profesionales que habitan a Puerto Colombia, se elaboró para cada jefe de familia un círculo horario correspondiente a la vida normal de los días corrientes; un cuestionario igual se graficó para el ama del hogar, con lo que se consiguieron datos completos para la rutina de la vida familiar.

Se obtuvo de los informadores una clasificación del uso de su tiempo así: hora de levantarse, tiempo empleado en aseo per- 
sonal y desayuno, tiempo destinado a trasladarse hasta el lugar de trabajo, tiempo necesario para regresar al hogar cuando la comida del mediodía se realizaba en la casa, tiempo destinado a la comida, incluída siesta si la había, tiempo de regreso al trabajo y sistema de transporte, horario de trabajo por la tarde, hora de salida, sistema de regreso incluyendo tiempos intermedios dedicados a la conversación con los vecinos, visita de cantinas y otros, hora de regreso al hogar, tiempo destinado a la comida, tiempo entre comida y sueño y tiempo destinado a dormir.

La idea básica de este análisis fue la de poder verificar las concordancias y diferencias de las estructuras sociales y familiares; partiendo del hecho de que el ritmo de vida familiar está condicionado en gran parte al horario del jefe de familia, mientras que la armonía familiar y la educación de los hijos dependen casi por completo del horario materno.

Se establecieron las categorías socio-profesionales dominantes y comunes a la población y se analizaron para cada una de ellas, además de los ritmos horarios ya descritos, el valor del tiempo de ausencia y de presencia en el hogar.

Se tuvo en cuenta y se le dio una alta significación al valor tanto objetivo como subjetivo del sentimiento de fatiga, precisándose las necesidades sentidas de descanso y las actitudes referidas al mismo, a lo que se añadieron las ideaciones respecto al trabajo.

Para el ama de casa se repitieron iguales diagramas de horario con el mismo procedimiento investigativo y se evaluó cuidadosamente sobre las profesiones ejercidas por fuera de la hogareña; la relación entre horario de trabajo doméstico; el uso de tiempo de reposo; los motivos de fatiga, $y$, finalmente, los razonamientos para explicar los trabajos no hogareños y la aspiración por trabajos profesionales. En aquellos casos en que la mujer necesita aportar ingresos al presupuesto familiar, se estableció la relación entre su trabajo y la categoría socio-profesional del jefe de familia.

Tomando en cuenta la composición de la población, en base a categorías socio-profesionales representativas del conjunto de la comunidad, se consideró conveniente analizar los grupos de obreros, intermediarios, comerciantes, empleados, pescadores y gentes sin trabajo.

Otras categorías de trabajo no fueron tomadas en cuenta 
por su poca significación y escasa frecuencia. Para el grupo dedicado al comercio se halló que en realidad debía ser definido como comercio propio, ya que se trata en la inmensa mayoría de los casos de personas que atienden su comercio sin tener empleados, puesto que el tamaño de la empresa es de tipo familiar.

Se estableció como categoría especial la de "gentes sin trabajo", para valorar la posición de ciertas personas que se hallan desempleadas pero cuya situación no es momentánea sino que perdura por años. Se trata de personas que no pueden ser clasificadas como inválidas, pero que actúan como tales por no haber conseguido adaptarse a nuevas formas de trabajo cuando fue cerrado el puerto marítimo.

Conviene aclarar que dentro de estas categorías socio-profesionales se dan ciertas condiciones específicas y algunas variantes para un mismo grupo; así, hallamos tipos de trabajo esporádico, como el de algunos obreros que trabajan en más de un oficio en forma casi permanente.

Entre los pescadores el trabajo artesanal está muy relacionado con su profesión misma. Podría decirse que en general se trata de una ampliación de horas en el propio oficio.

En las categorías de empleados y comerciantes es corriente la existencia de ocupaciones profesionales adicionales.

Buen número de gentes se ocupan en ciertos trabajos domésticos o de mantenimiento de la casa, pero no se consideran en este aparte por no tener un carácter remunerativo destinado a aumentar los ingresos; son trabajos que sólo significan ahorro.

Como puede establecerse una división clara entre las gentes que viven y trabajan en Puerto Colombia y aquellas otras que trabajan en Barranquilla, se dio importancia a los sistemas de transporte.

EL JEFE DEL HOGAR, HORARIO, DESPLAZAMIENTOS Y FATIGA

Para los habitantes de Puerto Colombia la primera división puede establecerse en dos grupos: los que trabajan fuera de la bocalidad y aquellos que no necesitan salir de ella para su trabajo diario.

Entre las personas que trabajan fuera de Puerto Colombia el factor "distancia-tiempo" constituye un elemento importante, 
ya que en realidad afecta el presupuesto diario de gastos y la parte del tiempo destinada al traslado.

De los 28 casos estudiados como representativos, sólo dos corresponden a personas que poseen vehículo propio: una es propietaria de una camioneta de uso exclusivo para su familia; la otra es el dueño de un taxi y por tanto esta propiedad constituye en realidad un elemento de trabajo.

Esporádicamente algunas personas son dueñas de caballerías, pero no puede considerarse que éstas sean destinadas al transporte. El reparto del pan se hace a lomo de burro, así como el reparto del carbón, casos que quedan clasificados como medio de transporte de mercancías y no como vehículos de transporte humano, razón por la cual no entran en nuestro análisis.

\section{Del domicilio al trabajo.}

La mayoría de los obreros que trabajan fuera de Puerto Colombia están empleados en los servicios del Terminal Marítimo. $\mathrm{Su}$ traslado hasta Barranquilla se hace por medio de buses de la Empresa Marítima y el tiempo transcurrido en cada uno de los viajes es aproximadamente de 35 minutos. Para otras personas que trabajan en Barranquilla, como empleados, intermediarios o lo pescadores de Bocas de Ceniza, sólo queda el recurso de las líneas intermunicipales de buses, que por sus salidas a horas fijas y por la serie de paradas para tomar pasajeros gastan un tiempo mayor que los buses del terminal.

Entre los dos extremos el promedio del tiempo de transporte es de una hora veinte minutos en viaje de ida y regreso, ya que las personas que trabajan en Barranquilla no regresan al mediodía para almorzar en la casa.

Corresponde a estas gentes algo más de media jornada por semana destinada simplemente a transporte; debe añadirse, además, el tiempo de espera para tomar los buses, que tienen horas fijas de partida y que sólo en las ocasiones en que han alcanzado pleno cupo anticipan su salida; el período de espera puede considerarse fatigante y enerva al individuo, ya que es necesario subir al bus para obtener un puesto, $\mathrm{y}$, tanto la temperatura como la incomodidad hacen difícil el tiempo entre el momento en que el individuo ha subido al bus y el arranque de éste. No obstante, para ciertas personas esta espera es utilizada como una distracción en el sentido de que les permite establecer conversación 
y comentarios con los vecinos y conocidos; así circulan noticias de la ciudad al pueblo y se comentan los intereses de la comunidad. Por lo tanto puede considerarse que el tiempo de espera aumenta en un cincuenta por ciento el tiempo de transporte. El viaje puede constituír una satisfacción en las horas muy calurosas, puesto que la brisa por la velocidad del vehículo es apreciada por el público, aun cuando por otra parte los buses son poco confortables por la mala distribución y tapicería de las bancas.

Para las personas que viven y trabajan en Puerto Colombia, puede considerarse que el promedio máximo a pie se limita a unos veinte minutos para los cuatro viajes diarios; por otra parte, es numeroso el grupo de gentes que trabajan en el propio domicilio o muy cercano a él.

Algunas personas, por razón de trabajo o negocios, se ven obligadas a un viaje semanal a Barranquilla, mientras que ciertos comerciantes deben viajar todos los días a fin de proveerse de mercancías de venta diaria, como es el caso de carnes, verduras y ciertos alimentos que pueden conseguirse a precios más baratos en Barranquilla.

Tiempo necesario para concurrir al trabajo.

Hemos señalado la importancia dada a este factor; por tanto se reúnen en un cuadro los promedios de tiempo de transporte y los sistemas, costos y horas empleadas, relacionado a categorías socio-profesionales.

La importancia de estos factores referida tanto a la rutina diaria total como a los demás elementos analizados, figura en nuestras conclusiones.

Tiempo de trabajo y horarios.

Los promedios de trabajo corresponden a categorías socioprofesionales diferentes y van desde los horarios fijos de los empleados a los horarios intermitentes y absolutamente irregulares de los obreros del Terminal Marítimo, cuyos días, horas y turnos corresponden con el horario de llegada de los buques. Lo común es que un obrero del Terminal trabaje de tres a cuatro 


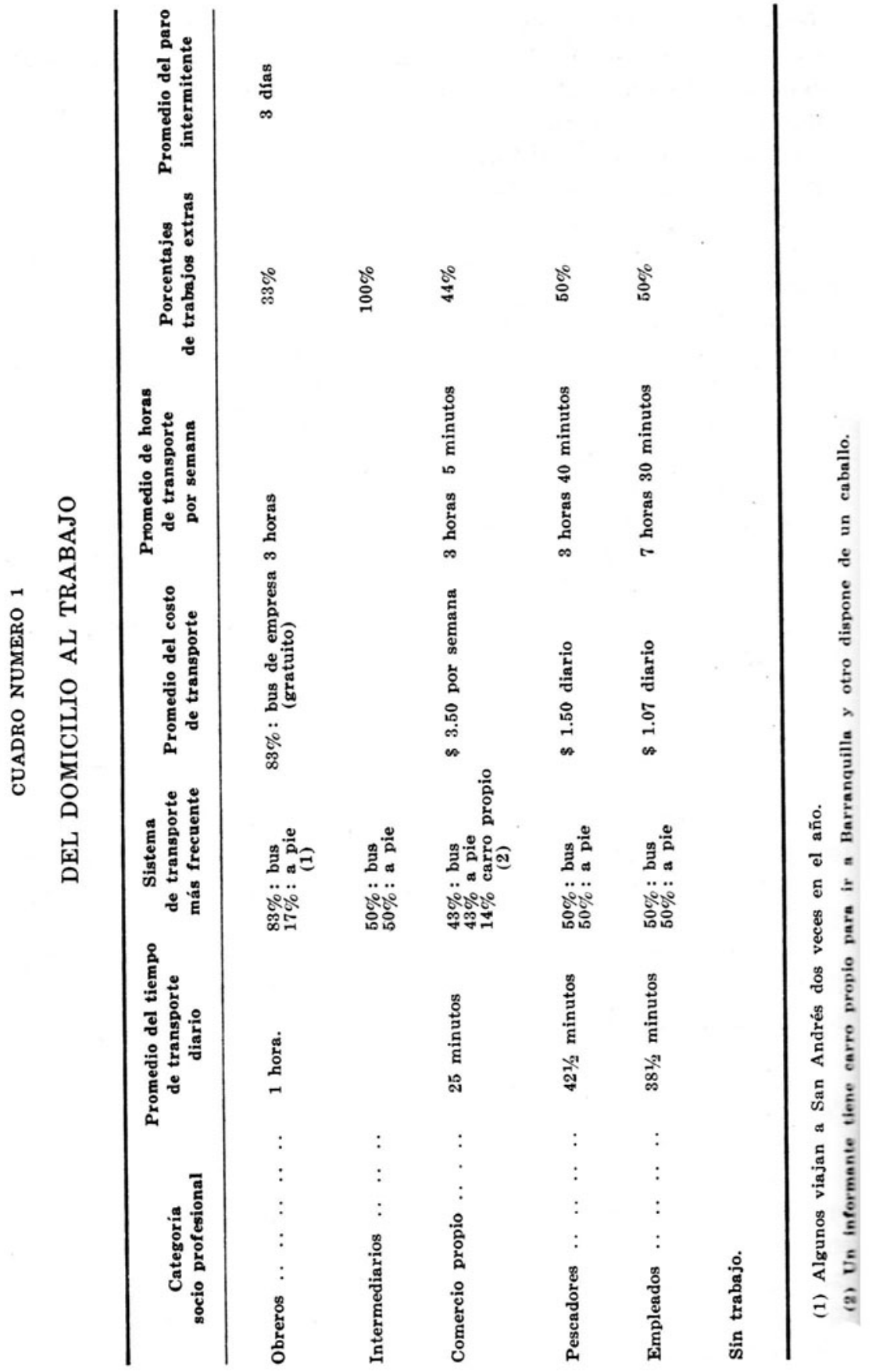


días semanales; para algunos obreros se reduce este ritmo hasta a uno o dos turnos por semana, mientras que otros tienen un trabajo fijo diario como obreros de tiempo completo. El promedio calculado de trabajo por turno es de 8 a 9 horas, lo que no obsta para que en ocasiones pueda ser prolongado hasta por 14 horas. Otros obreros, tanto de Puerto Colombia como de Barranquilla, tienen la jornada regular diaria de 8 horas.

Para los intermediarios el horario es más irregular, principalmente porque algunos se dedican a este trabajo como sistema para obtener ingresos extras.

Para los empleados, el promedio de trabajo es de 11 horas 35 minutos por día. Este promedio, que parece muy alto, es consecuencia de que algunos empleados figuran con 18 horas 30 minutos diarios, lo que equivale en realidad a una permanencia día y noche en la empresa; se trata en realidad de celadores que disponen solamente de media hora para almuerzo al mediodía y dos horas para comida en la noche; otro ejemplo lo constituye uno que trabaja de las cuatro de la tarde a las doce de la noche, aproximadamente, en un quiosco-restaurante. Agreguemos que otro, además de ser obrero esporádico en el Terminal, trabaja doce horas diarias durante los días libres como camarero en un hotel, o el empleado como celador nocturno que luégo aprovecha seis horas diurnas para trabajar como intermediario. Se trata de un tipo de trabajo no equiparable en ningún caso al de un obrero de una fábrica; su permanencia en la empresa no significa una actividad continuada en todo momento, pero en la cuenta horaria, estos casos hacen subir las horas de ocupación a un promedio de más de 11 horas 30 minutos, para el grupo que hemos calificado como empleados.

Por tanto, es necesario tener en cuenta una serie de factores: el gran número de horas de los empleados se ocupa en un tipo de trabajo que no exige gran esfuerzo. Son muy inferiores a las que se obtienen en lo que verdaderamente puede considerarse como empleo cuando nos referimos a la ocupación en una oficina; no obstante, al tratar de conseguir este sobresueldo se afecta el ritmo de trabajo, las horas de permanencia en el hogar y aun en ocasiones las horas de sueño se confunden con las del empleo, como en el caso del celador de tiempo total.

El grupo de pescadores tiene que dividirse entre los que pescan en la bahía frente a Puerto Colombia y aquellos que se tras- 
ladan a Barranquilla para pescar en Bocas de Ceniza; los primeros durante sus días de trabajo presentan un promedio de ocupación entre 4 y 5 horas, según lo afortunado de la pesca, mientras que los últimos dedican un promedio de 12 horas de permanencia en el trabajo. No obstante estos últimos tienen un tipo de trabajo temporal, ya que durante los meses de fuerte brisa, diciembre a marzo, permanecen inactivos. Hemos considerado para nuestra evaluación que el valor horario de trabajo se refiere a los meses dedicados a la pesca.

El grupo clasificado como personas con comercio propio, presenta un promedio de 10 horas dedicadas al trabajo por día, promedio que en realidad sería más alto si considerásemos que no existen días feriados para la casi totalidad de los comerciantes, dado que es precisamente el día festivo cuando afluye mayor población de Barranquilla a Puerto Colombia.

La interrupción del trabajo al mediodía con finalidad de almuerzo, permite establecer la división entre el grupo de gentes que almuerzan en su propio domicilio y aquellas que no almuerzan en su casa. Quienes trabajan en Barranquilla no regresan a su hogar en horas de almuerzo. En cuanto al tiempo de descanso (siesta o permanencia en el hogar), es mayor para quienes viven en Puerto Colombia; no obstante se dan también formas mixtas, ya que los obreros del Terminal, con trabajo esporádico, no regresan en horas de almuerzo a la casa cuando trabajan en Barranquilla, y se comportan como los residentes de Puerto Colombia en los días que no viajan al Terminal Marítimo.

Horario de vida diaria.

Partiendo del análisis de 27 familias, representado por 6 obreros, 2 intermediarios, 8 comerciantes, 2 pescadores, $8 \mathrm{em}$ pleados y 1 sin trabajo, establecimos las horas promedio para levantarse, salir de la casa, entrada y salida del trabajo, regreso al hogar y hora de acostarse.

Hallamos que quienes primero despiertan son los sin trabajo, a las 5:00 a. m.; los comerciantes y pescadores, a las 5:15 a. m.; los obreros, a las 5:30 a. m.; los empleados, a las $6: 15$ a. m., y por último, los intermediarios, a las 8:00 a. m. El promedio para la población total corresponde a las 5:50 a. m. 
El orden de salida de la casa hacia el trabajo es: primero, los pescadores, a las 6:00 a. m.; obreros y empleados, a las 6:30 a. m.; comerciantes, a las 6:40 a. m., y por último, los intermediarios, a las 9:00 a. m. El promedio de salida del hogar para la población total corresponde a las 6:40 a. m.

La entrada al trabajo comienza a las 6:40 a. m. para los comerciantes; a las 7:00 a. m. para los obreros; a las 7:20 a. m. para los empleados; a las 7:40 a. m. para los pescadores, $\mathrm{y}$ a las 9:30 a. m. para los intermediarios. El promedio total para el comienzo del trabajo en la población corresponde a las 7:15 a. m.

El trabajo termina por la tarde en el siguiente orden: intermediarios, a las 5:00 p. m.; obreros, a las 6:15 p. m.; comerciantes, a las $6: 30$ p. m.; empleados, a las $6: 50$ p. m., y pescadores, a las 7:15 p. m. Para la población total el promedio establece la hora de 6:30 p. m. como final de jornada, elemento que corresponde exactamente a los comerciantes, como es típico en todas las comunidades.

Para los obreros la hora de regreso al hogar se sitúa entre las 5:30 p. m. y las 7:00 p. m.; sólo debe exceptuarse el caso de los obreros del Terminal supeditados al turno de la llegada de los buques.

El grupo de empleados debe dividirse en los oficinistas, que regresan entre las 6:00 p. m. y las 7:00 p. m., y otros como camareros y empleados en cantinas, que normalmente prestan servicio hasta las 9 de la noche en días normales y hasta las 12:00 p. m. en días festivos.

Un factor personal interviene para el tiempo destinado entre salida del trabajo y llegada al hogar. La mayoría de las gentes consideran importante este tiempo, ya que lo dedican a conversación social. En realidad la falta de sistemas recreativos ha sido compensada por la reunión y la conversación, dedicándose a esto de una hora a hora y media diaria.

Para los obreros que trabajan en Barranquilla se da generalmente una ocupación intermedia; a la salida del trabajo dedican aproximadamente entre media hora y una hora a la compra de parte de mercado familiar, puesto que los precios son más bajos en Barranquilla. Realizada la compra, regresan cuanto antes. El cansancio físico se acusa por la actitud más común de llegar a la casa y recostarse.

Se nota gran regularidad en la hora de acostarse; única- 
mente los sábados y domingos se altera el ritmo con características personales. En ocasiones la hora de regreso se retrasa por la invitación ofrecida o recibida en el café o el bar, y depende del dinero disponible para el consumo de bebidas.

Los intermediarios tienen como hora de acostarse las 8:00 p. m.; los empleados y comerciantes, a las 9:15 p. m.; los pescadores, a las 9:45 p. m., mientras que los obreros, con execpción de los días en que se presenta trabajo nocturno, se retiran a las $9: 50$ p. m.

Trabajo, horarios y actitudes asociadas.

Damos a continuación, por categorías socio-profesionales, horarios de trabajo e interrupciones, horas destinadas a alimentación, actividades durante el tiempo de regreso al hogar y trabajos extras nocturnos. Esto nos permite establecer por comparación con los demás datos recogidos unos valores relativos de actitudes personales.

Hallamos que la hora de comienzo al trabajo oscila entre las 6:40 a. m. y las 9:30 a. m., siendo los comerciantes quienes primero comienzan y los intermediarios quienes empiezan más tarde.

La hora del almuerzo al mediodía comienza a las 12:00 m. para todos, si bien los obreros, intermediarios y pescadores, sólo disponen de una hora, los empleados de una hora y media, y los comerciantes de dos horas, compensando estos últimos con la siesta su hora de anticipación matutina del trabajo.

En cuanto a la terminación de su jornada por la tarde, quienes primero acaban son los intermediarios; siguen los obreros y más tarde los comerciantes, empleados y pescadores.

La actividad durante el tiempo de regreso a la casa, está destinada esencialmente a la conversación con otras personas. Constituye en realidad un tiempo de integración social, que las gentes comparten interesándose por el comentario de la vida personal y colectiva.

Para la categoría obreros, debe tenerse en cuenta el tipo de trabajo de turno esporádico condicionado por la llegada de los buques; en el cuadro número 2, queda incluído el total de horas trabajadas sin un horario fijo, inclusive las horas nocturnas. 


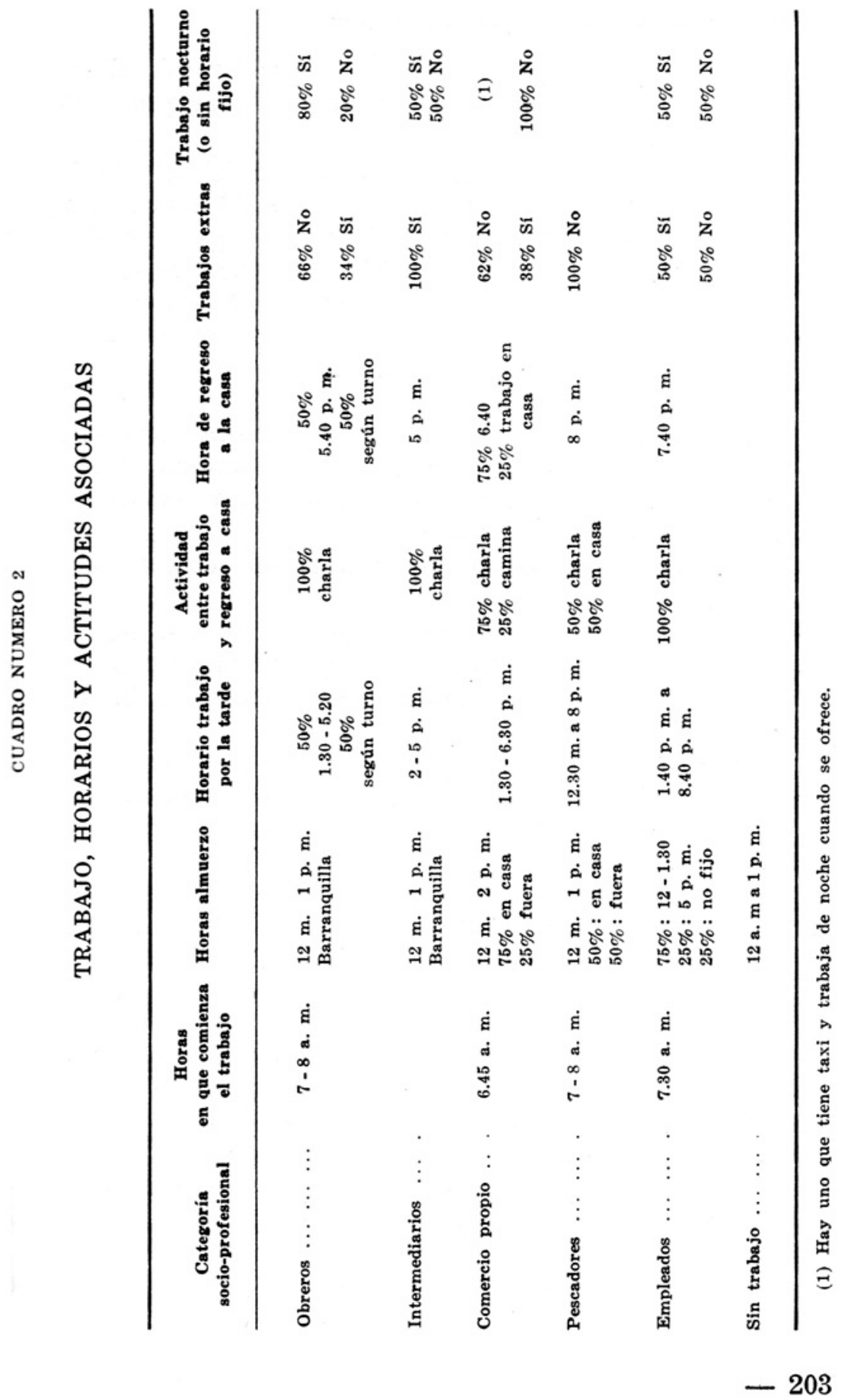


Presencia en la casa del jefe del hogar.

$\mathrm{Si}$ bien en otro aparte se toma en consideración el aspecto activo de presencia en el hogar, el análisis horario nos proporciona los datos que siguen:

El total semanal de horas de residencia del jefe del hogar en su casa, consideradas como activas, es de 49 horas, 40 minutos para los pescadores; 44 horas, 25 minutos para los obreros; 36 horas para los comerciantes; 34 horas para los empleados, y 28 horas para los intermediarios; debiendo considerarse como no representativo el grupo de los sin trabajo, que prácticamente se quedan todo el día en la casa.

El número de horas de residencia en el hogar durante los días entre semana, oscila entre 3 horas, 30 minutos para los obreros; 4 horas para los intermediarios y empleados; 4 horas, 50 minutos para los comerciantes; 7 horas para los pescadores, y 11 horas para los sin trabajo.

En líneas generales este tiempo es del doble en los días festivos y domingos.

Por otra parte, los obreros y empleados residen mucho más tiempo en la casa los sábados, correspondiendo el máximo de 9 horas, 40 minutos a los empleados, y el mínimo de 5 horas, 50 minutos para los obreros.

La presencia en la casa debe evaluarse tanto en su tiempo total, como referida a las actividades durante la permanencia en el hogar. La evaluación de los tiempos totales es la siguiente, en promedio diario:

Quienes permanecen más en la casa son los pescadores, con un promedio de 5 horas, 25 minutos por día; siguen los sin trabajo, con 5 horas; los empleados y obreros, con 2 horas, 50 minutos; los comerciantes, con 2 horas, 30 minutos, y, finalmente, los intermediarios, con 1 hora, 30 minutos.

El promedio semanal es muy similar en orden y se establece así: se hallan en el hogar durante 37 horas, 40 minutos, los pescadores; 35 horas, los sin trabajo y obreros; 16 horas, los comerciantes; 12 horas, 20 minutos, los empleados, y 10 horas, 30 minutos, los intermediarios. La diferencia procede de las personas que durante los días festivos dedican parte de su horario al trabajo.

Si consideramos ahora la actitud en la casa durante este tiempo de permanencia, vemos que los sin trabajo ayudan a cier- 
tas labores domésticas durante 1 hora diaria; siguen los obreros, quienes dedican 45 minutos por día; los pescadores, con $12 \mathrm{mi}$ nutos, y puede considerarse como que ayudan mucho menos los de las categorías socio-profesionales restantes.

Con referencia al tiempo de permanencia en el hogar dedicado a los hijos, hallamos los valores siguientes para los días de trabajo entre semana: los empleados dedican a sus hijos 1 hora, 12 minutos; los intermediarios y comerciantes, 1 hora, y los obreros, 45 minutos.

Este valor se altera en los días festivos, en que los empleados y comerciantes dedican a sus hijos 3 horas, y los obreros 2 horas, 30 minutos. Las demás categorías dedican muy poco tiempo a la atención de los hijos.

Por otra parte, durante las horas de permanencia en la casa, en el tiempo dedicado a distracción, conversación, audición de radio, lectura, etc., hallamos la siguiente distribución: los pescadores, 5 horas, 12 minutos; los sin trabajo, 4 horas; los obreros, 2 horas, 30 minutos; los comerciantes, 1 hora, 50 minutos; los empleados, 1 hora, 40 minutos, y, finalmente, los intermediarios, 1 hora.

En el estudio de la estructura familiar estos datos son de importancia decisiva; las conclusiones que se derivan de su evaluación no se incluyen en el presente estudio, que puede considerarse como solamente descriptivo, si bien es fácil evaluar la importancia y observar la inter-relación de los datos presentados aquí, para la comprensión de la dinámica socio-familiar.

Tiempo de ausencia de la casa por categorías socio-profesionales.

Quienes presentan un horario más alto de ausencia durante los días de trabajo semanal, son los empleados, con 12 horas, 12 minutos; siguen los obreros y quienes tienen comercio propio, con 11 horas; los pescadores, con 9 horas; los intermediarios, con 7 horas, 30 minutos; y el menor tiempo, 5 horas por día, corresponde a los sin trabajo.

Durante los días festivos, el jefe del hogar se queda mucho más tiempo en la casa, pero se altera el orden por categorías. Así, son ahora los pescadores quienes se ausentan durante 8 horas; luégo los comerciantes, con 7 horas, 6 minutos; los intermediarios, con 6 horas; los obreros, con 5 horas, 48 minutos, y los empleados, con 4 horas, 30 minutos. 
Si consideramos el promedio total semanal, incluídos los días festivos, hallamos el siguiente horario:

Quienes más tiempo están ausentes son los comerciantes, con 73 horas, 30 minutos, por semana; siguen los empleados, con 68 horas, 35 minutos; los pescadores, con 53 horas; intermediarios, con 51 horas; obreros, 43 horas, y los sin trabajo, con 35 horas, siendo estos últimos a quienes hallamos casi siempre en la casa.

Es conveniente advertir que dentro de una misma categoría socio-profesional se dan variantes y actitudes diferentes.

Para los obreros del Terminal, las ausencias presentan el carácter irregular del tipo de trabajo; como promedio son tres o cuatro días por semana durante un plazo de 10 a 12 horas mínimo. Para los obreros de otras empresas la ausencia es menor y puede considerarse aproximada a $\mathbf{1 1}$ horas diarias (ocho de trabajo y el resto en recreación fuera de la casa). Como forma intermedia hallamos los obreros del Terminal que trabajan como empleados en los días no ocupados en el puerto; para esta categoría la ausencia equivale a 14 horas durante cuatro días por semana.

Para la categoría de empleados, el promedio señalado con 12 horas, 12 minutos, varía de un mínimo de 8 horas, y el máximo en 19, lo que depende del hecho de que algunos de ellos trabajan en tiempo extra como contabilistas, profesores, etc.

La mayoría de los incluídos en la categoría de comercio propio, trabaja en el mismo domicilio, si consideramos su tiempo dedicado al trabajo como ausencia del hogar, hallamos un promedio de 10 horas, 20 minutos, con un mínimo de 8 y máximo de 14 ; naturalmente en esta categoría es difícil establecer una discriminación clara por ser la residencia y negocio un mismo lugar.

Si pasamos del ritmo diario al semanal con relación al trabajo y descanso en la casa, se altera notablemente. La fluctuación general oscila de 34 a 60 horas para el conjunto, con variantes notables. Así, los obreros del Terminal que no trabajan sino tres o cuatro días, permanecen otros tantos en la casa, lo que da un tiempo de descanso y residencia en el hogar muy alto.

Para los intermediarios la variación es de 42 a 60 horas; para los pescadores, de 42 a 78 horas; para los empleados, de 56 a 80 horas, y, finalmente, quienes tienen comercio propio, de 54 a 98 horas semanales, si bien estos últimos están casi siempre en contacto directo con los problemas familiares, porque en 
la mayoría de los casos residen junto a su establecimiento, como indicamos anteriormente.

\section{Descanso.}

Para la mayoría de las gentes de Puerto Colombia, la falta de sistemas de recreación hacen que ésta quede casi reducida al consumo de bebidas alcohólicas, lo que significa que el reposo y la no actividad constituyen el único sistema de recuperación personal.

Para los obreros del Terminal el descanso es casi equivalente a las horas de permanencia en el hogar, destinadas en lo posible al sueño y con la más alta proporción, como acabamos de anotar. No obstante, algunos de estos obreros, con una doble profesión (como la de camarero), nos dan los mínimos de descanso y permanencia en la casa, ya que destinan todas las demás horas; hasta se da el caso de uno de ellos que sólo reside en la casa durante ocho horas de sueño nocturno.

En la categoría de gentes con comercio propio (comerciantes, dueños de quioscos de comida y bebidas, etc.), el trabajo ocupa todos los días, incluídos los festivos; entre éstos es costumbre que tres o cuatro veces por mes tomen un día completo, sin fecha fija y escogido únicamente por el criterio de conveniencia personal, para descanso, viaje a Barranquilla, etc. Los dueños de tiendas, hoteles o compañías de buses, organizan su día de descanso semanal en función del público, y como su trabajo más intenso corresponde a los días festivos, tienen preferencia en escoger el día de descanso entre semana.

Para quienes manejan una pequeña industria, es la tarde del sábado y el día domingo, coincidiendo con los obreros y empleados.

El grupo de los intermediarios, no presenta un día fijo, y normalmente emplean los días festivos para aumentar los ingresos; no obstante, la mayoría de ellos actúa en estos días festivos residiendo en la casa las mismas horas que durante los días comunes de la semana.

\section{Presencia en el hogar.}

La importancia del tiempo de permanencia en la casa, debe enfocarse desde dos puntos de vista diferentes: el que la persona destina para sí misma y el tiempo en que colabora con los demás integrantes de la familia. 
El tiempo destinado al baño y desayuno en la primera hora de la mañana, significa para todas las categorías socio-profesionales estudiadas como de uso únicamente personal. Lo mismo sucede en la hora del almuerzo, para quienes lo realizan en su casa; cuando estas horas del mediodía ofrecen un sobrante antes de regresar al trabajo, se destina a la siesta; raramente representa una ayuda a la mujer en los quehaceres del hogar, y tampoco puede considerarse destinado a la atención de los hijos, aun cuando se den contactos educacionales que son siempre formulados como indicaciones, recomendaciones o amonestaciones y castigos.

Se valora mucho más el tiempo de reposo después del trabajo diario. Así vemos que el grupo de quienes tienen comercio propio acostumbra a quejarse de su falta de tiempo para descanso y manifiestan el deseo de poder descansar, como los obreros que llegan a la casa y reposan antes de la comida de la noche. Con todo, los obreros manifiestan como envidiable que el tendero pueda sentarse repetidamente durante el día en los intervalos en que no tiene que atender la clientela.

Para todo el conjunto estudiado es manifiesto el deseo de poder disponer de tiempo para quedarse en la casa y oír especialmente los programas de novelas radiales. Igualmente se considera importante y deseable disponer de tiempo para la conversación y el paseo.

Con todo, la necesidad más sentida es disponer de ingresos para diversiones como el cine y en especial para la cantina. La falta de dinero, o el aceptar la invitación de quien lo tiene y no poder corresponder a invitaciones recibidas, crea un verdadero sentimiento de frustración. Puede considerarse que esto constituye un núcleo importante en las actividades sociales del individuo; su "status" es afectado por esto.

Empleo del tiempo pasado en la casa.

Es general que el hombre no se ocupe en trabajos domésticos. Ayuda poco a la esposa y prácticamente no se ocupa de la educación de los hijos.

En ocasiones esporádicas el jefe de familia barre o limpis el patio y la entrada de la casa, y atiende las mejoras de ella cuando es de su propiedad (los arrendatarios manifiestan un franco descuido en la reparación de daños de uso), acostumbran 
a contratarse obreros de la construcción, por cuenta de los propietarios.

Esporádicamente el padre puede atender por un momento a alguno de los hijos de corta edad; dedica poco tiempo a la conversación o juego con los niños durante su permanencia en la casa; casi nunca los ayuda en sus tareas escolares, puesto que en muchos casos la generación de los padres es analfabeta o de muy bajo nivel educacional, y su interés se centra más en la comprobación de que sus hijos mejoran o saben más que él.

Los padres acostumbran atender ciertos quehaceres, como acompañar a sus hijos al consultorio médico, al dentista, o al cine, dos o cuatro veces al mes, pero raramente salen a pasear con ellos.

En el grupo obrero se nota un alto interés en la educación de los hijos; se desea que superen el nivel paterno, pero recae sobre la madre la atención del trabajo escolar. Hemos hallado cuatro familias obreras entre las estudiadas, en las que las hijas son maestras. Igual interés de superación intelectual se manifiesta por parte de los empleados, mientras que en la categoría de los comerciantes existe la tendencia a hacer que sus hijos se integren al trabajo o negocio del padre. Debe consignarse aquí que son las niñas quienes representan el mayor porcentaje interesado en mejorar a base del estudio escolar.

El conjunto de los empleados presenta el mayor número de horas dedicado a los hijos, si bien nunca pasa de media hora. Para el grupo con comercio propio, la relación de los hijos queda reducida al mínimo.

Se considera que es responsabilidad de la madre atender al vestido, lavado, comida y juego de los niños, y si la capacidad económica lo permite se consigue para ello la ayuda de personas de servicio, o en caso contrario se recurre a una de las hijas mayores, o familiares adultos.

Tiempo destinado al sueño.

Diferenciando entre sueño nocturno y siesta o sueño diurno, hallamos los siguientes promedios con respecto a la división socio-profesional:

De mayor a menor tiempo de sueño nocturno hallamos 9 horas para los intermediarios; 7 horas, 55 minutos para los comerciantes; 7 horas, 30 minutos para los pescadores y los sin trabajo, y 7 horas para los empleados y obreros. 
Con respecto a horas de sueño diurno, vemos que los empleados dedican 1 hora, 30 minutos; los obreros, intermediarios y comerciantes, 1 hora; los sin trabajo, 30 minutos, y que entre los pescadores no se acostumbra la siesta.

Resumidos los totales de horas dedicadas a dormir, vemos que los obreros, intermediarios y comerciantes presentan un total diario de 8 horas, 5 minutos; los sin trabajo, 8 horas; los empleados, 7 horas, 35 minutos, y los pescadores, 7 horas, 5 minutos.

\section{La fatiga.}

La fatiga se relaciona con múltiples factores; es en parte consecuencia del trabajo, del tipo de horario y de los sistemas de transporte entre el lugar del trabajo y el hogar. Su apreciación depende en gran parte de contenidos subjetivos que vienen a sumarse al cansancio físico real.

Otros elementos, como una alimentación deficiente o mal balanceada, el horario destinado al sueño, la ingestión de bebidas alcohólicas, afectan el rendimiento del trabajo; intervienen igualmente otros factores como el estado de ánimo, las consideraciones ideativas con respecto al trabajo, el clima, los ruidos, el confort, el horario, etc.

Entre los grupos socio-económicos estudiados hallamos los elementos siguientes: para los obreros del Terminal, se considera el turno según sea de día o nocturno, y se atribuye a cada uno de ellos, el tipo de fatiga que es descrito como más importante, durante el trabajo diurno cuando no se tiene protección del sol, en cuyo caso el calor es considerado como la causa del cansancio; no obstante, se prefiere el horario diurno al nocturno, puesto que en este caso si bien el calor es menor, la plaga de mosquitos constituye la incomodidad más temida.

Para algunos de los que constituyen el grupo socio-económico descrito como gentes con comercio propio, el cansancio y la fatiga se atribuyen a la dispersión en trabajos distintos. Dentro de este grupo hay algunas personas que no manifiestan fatiga, que consideran su trabajo como agradable y que por tener su pequeño negocio en la casa, en realidad no se ven obligados a un tipo de ocupación francamente fatigante. Todo indica que para este grupo lo que constituye causa de fatiga es la actividad monótona, que hace considerar aburridor el curso diario de tarea. 
Los empleados expresan en forma distinta el cansancio, son ellos quienes más se quejan de lo fatigante del transporte para llegar al lugar de trabajo desde su casa. El factor distancia parece ser decisivo. Nuestra observación nos permite afirmar que se trata del grupo que menos fatiga demuestra al llegar a su casa; su trabajo no es pesado y tienen tiempo suficiente para descansar y charlar en las horas del mediodía, y especialmente cuando salen de la oficina por la tarde, constituyendo esto casi un sistema de recreación.

El estudio de los horarios de cada uno de los grupos permite afirmar que la fatiga es esencialmente originada más por criterios subjetivos que por criterios físicos; así, la situación económica relacionada al trabajo, viene a interferir los elementos que se originan en verdadero desgaste de orden físico, hasta el punto que la preocupación entre trabajo y salario percibido, y la relación entre salario percibido y necesidades familiares a cubrir, constituyen para la mayoría de las gentes un problema que si bien se relaciona indirectamente, actúa en realidad como elemento desesperante y fatigante con respecto a la vida diaria del individuo.

En el proceso de análisis de nuestras encuestas ha sido posible observar repetidamente que el nivel de vida de los obreros, cuyo sueldo es realmente insuficiente y cuyas dificultades para cubrir las necesidades familiares son grandes, al compararlo con la situación de los comerciantes cuya entrada monetaria es cuatro veces superior, y a la vez el trabajo real de cada grupo, no justifica la diferencia expresada en términos de fatiga sino que se explica única y exclusivamente como algo relativo a una ideación entre trabajo realizado, valor humano de este trabajo y percepción económica de horarios con respecto a aquél. Así, la fatiga que acusa el grupo de intermediarios no corresponde al esfuerzo físico sino a sentimientos subjetivos, pero estos últimos actúan como individuos que muestran más cansancio al final de la jornada.

Es a nivel del grupo de empleados donde encontramos la mayor preocupación, y el esfuerzo máximo tratando de alcanzar mejoría en el nivel de vida familiar. Son los empleados quienes buscan más comodidades, quienes tratan de vivir mejor, y quienes manifiestan una real preocupación e interés para mejorar su cultura presente. 
La apreciación de la fatiga manifiesta que, evidentemente, está cargada de elementos subjetivos, nos informa sobre el grado de aceptación o de protesta con respecto al trabajo.

Entre las causas a las que se atribuye la fatiga, la clase de trabajo no parece ocupar en realidad el primer lugar; en cambio, las condiciones en que se desarrolla el trabajo parecen ser más importantes. El tiempo de duración del trabajo es para los obreros del Terminal Marítimo el origen de la justificación de la fatiga; la jornada de trabajo a veces se prolonga mucho más que el horario normal de un obrero industrial, explicada la queja en parte por este mayor número de horas de las cuales las últimas se consideran francamente pesadas; descubrimos, no obstante, que es el ruido, la insolación o la plaga de mosquitos por la noche, más que la irregularidad del horario. El factor de la inestabilidad en el sentido de desconocer cuándo será encargado el próximo trabajo, produce un elemento de protesta, que generalmente se manifiesta en términos de un trabajo mal pagado, siendo éste un proceso de franca proyección racionalizadora.

Otro elemento relacionado con la fatiga, para quienes al mediodía no regresan a su casa en hora de almuerzo, es atribuído, con razón o no, a la consideración de que el no poder regresar a la casa es más enervante que el trabajo mismo.

Los términos en que se expresa la causa de fatiga son generalmente vagos, a veces se formulan como dificultades de dinero, no poder atender a todas las necesidades con un trabajo no deseado por poco remunerativo, como problema de que a pesar de que se trabaja no puede acabarse con las deudas, con los préstamos, etc., es decir, que no se consigue equilibrar el presupuesto por más que se trabaje. Ya hemos señalado anteriormente que uno de los problemas para la mayoría de estas gentes es no disponer de dinero suficiente para poder mantener el "status" de aceptar una invitación, de devolverla en forma oportuna o de poder invitar a sus amigos en los momentos que se pasan en la cantina; igualmente se siente la necesidad de lograr ingresos suficientes para mantener el prestigio del vestido. Es notorio el interés en conseguir que los familiares, y aun los hijos pequeños, dispongan de vestido no sólo limpio, cosa que siempre se mantiene, sino además nuevo. Igualmente existe la preocupación por alcanzar el pago de la educación de los hijos, para quienes se desea francamente un mayor nivel que el paterno. 
Sin duda el ingreso percibido por el trabajo, generalmente siempre inferior a lo que se desea, constituye una causa de tensión, enerva al individuo y produce un mecanismo de huída, cuya manifestación es este número de horas dedicadas a la bebida o al sueño diurno, en lo que el individuo halla en parte una fuga a su tensión.

Existe una relación entre el tiempo de viaje y la fatiga, si bien es aún la espera más enervante que el viaje mismo.

Es curioso comprobar que trabajos similares realizados en otros países manifiestan que el ruido en la casa es uno de los elementos más importantes en la sensación de falta de confort o fatiga. Para los diversos grupos analizados por nosotros en Puerto Colombia, puede afirmarse respecto al ruido que es un elemento considerado como indiferente y que interviene en débil proporción como causante de molestia; la mayoría de las gentes usa sus radios francamente ruidosos, hasta el punto de que muchas veces se interfieren con el de los vecinos, y es curioso, molesta más al jefe de la familia el ruido que pueda producir el juego de los niños, que el ruido intencional del radio.

Otro elemento de fatiga es atribuído a la incomodidad de vida en la casa, no obstante que entre las diferentes categorías socio-profesionales, la casa no varía extraordinariamente; los obreros acostumbran a quejarse más de las condiciones de las casas en que tienen que vivir y de la incomodidad que se origina por el exceso de personas en un número reducido de metros cuadrados de construcción.

El análisis y la apreciación de las causas de fatiga demuestra que las gentes consideran como peor la situación del obrero y como menos fatigante la del empleado, pero las variaciones de tipo personal e individual relativas a la edad, estructura familiar, complican extraordinariamente la apreciación de los elementos de fatiga. A través de las situaciones estudiadas la imbricación de diferentes problemas nos permite afirmar en líneas generales que la relación más importante es de tipo ideacional y que ella se cimenta sobre la relación entre el problema de los salarios y el nivel de vida real al nivel de vida deseado.

El gráfico número 1 resume cinco casos que representan los horarios más típicos para el grupo de jefes del hogar, según categorías socio-profesionales. 


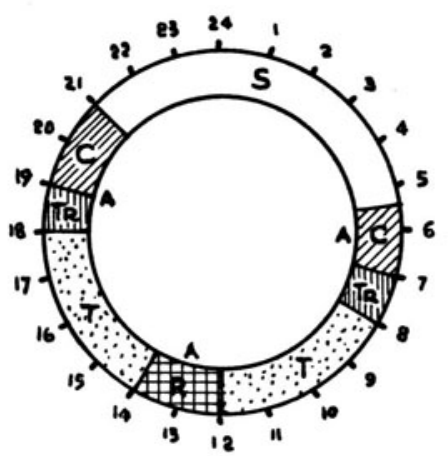

EMPLEADO (9)

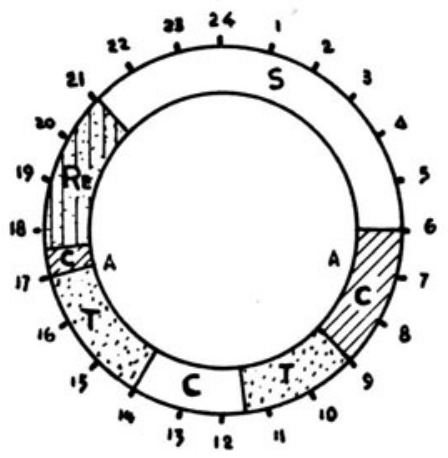

NEGOCIO PROPIO-INDUST. CASERA

(12)

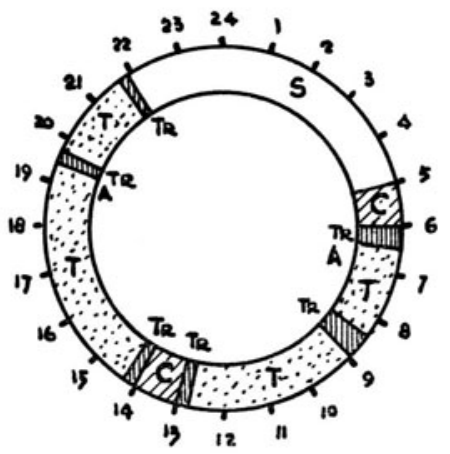

NEGOCIO PROPIO (1)

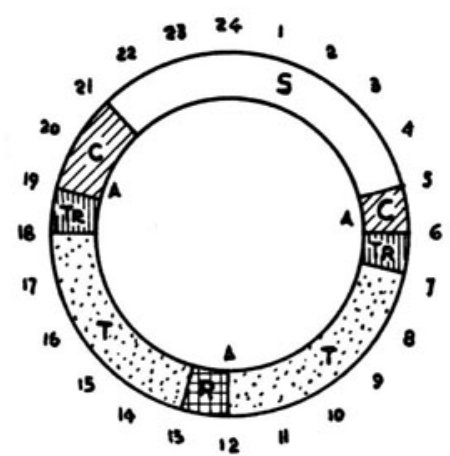

OBRERO (4)

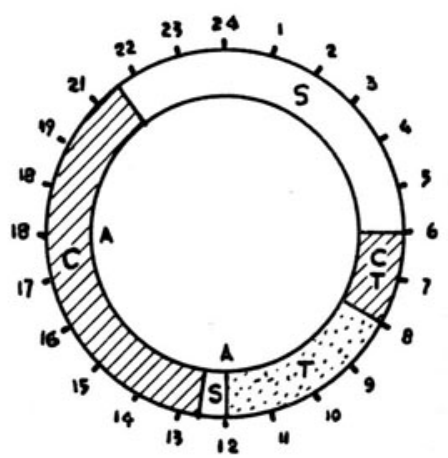

PESCADOR (8)

CONVENCIONES

$\square$ S - SUEÑo

WIIIIA C = CASA

पIIIIII TR: TRANSPORTE

T. TRABAJO

册册册 $R$ - RESTAURANTE

[AHET RE" RECREACION

$A$ A $=$ COMIDA 


\section{LA MADRE: TRABAJO DOMESTICO}

\section{Y TRABAJO PROFESIONAL}

El ritmo de la vida familiar se modela de acuerdo con el trabajo del padre, a la vez que la armonía familiar y la educación de los hijos depende en forma prácticamente total de la facilidad o de las dificultades que halla la madre en su trabajo casero o profesional, así como del grado de fatiga sentida por ella, y de los horarios que le son impuestos.

Para evaluar la importancia de estos elementos, anotamos las profesiones ejercidas por las mujeres que trabajan, sus horarios, el tiempo pasado fuera del hogar, el factor transporte, etc. El estudio del trabajo doméstico y familiar, su duración, la ayuda recibida de otros miembros de la familia o personas extrañas, permitieron establecer un cuadro exacto del uso del tiempo.

Los motivos de fatiga, la posibilidad de descanso y la manera de utilizar sus tiempos diferenciales, nos ayudan a discernir el grado de adaptación de las madres de familia a sus numerosos trabajos.

Simultáneo al análisis de estos horarios objetivos, se anotaron los valores de las motivaciones prácticas. Se buscaron las razones que justifican la escogencia de un oficio y este conjunto se relacionó con las categorías socio-profesionales del padre.

Finalmente, las aspiraciones de las mujeres con respecto a otros trabajos profesionales, fue enfocado desde puntos de vista como el deseo de continuar trabajando, o la valoración de si consideran todo trabajo extra como un obstáculo o una facilidad para su vida familiar y hogareña. Nos interesaba conocer si aquellas que no trabajan desean hacerlo en un futuro próximo. Igualmente se consideró necesario conocer hasta qué punto las mujeres eran partidarias de un trabajo profesional de tiempo parcial que signifique un aporte a la solución de los problemas económicos familiares, $\mathrm{y}$ aun conocer qué clase de trabajo era deseable.

Pretendíamos que esta investigación nos permitiese aclarar en forma precisa los problemas sociológicos que se plantean para las madres de familia, con respecto a la atención y educación de los hijos, y las consecuencias diferenciales producidas por el trabajo femenino en el hogar y fuera de éste. 
Del análisis se deduce que son muchas las mujeres que trabajan en un segundo oficio. Para la mayoría de ellas este trabajo extra se realiza en el mismo hogar; el menor número se dedica solamente al oficio doméstico; son menos las que trabajan el mayor tiempo como empleadas, y, finalmente, aparece el grupo de mujeres separadas del esposo y madres solteras que atienden su familia, quedando dentro de esta categoría un reducido número de viudas, si bien éstas generalmente tienen hijos mayores y se constituye un tipo familiar diferente, donde hallamos casi siempre una o varias hijas mayores que tienen una mejor preparación profesional y de quienes dependen los ingresos económicos.

El mayor porcentaje de las mujeres que trabajan en su propio hogar, ejerce labores que no requieren formación profesional. En el caso de las empleadas, casi todas tenían estudios mínimos, hasta segundo año de bachillerato, y su edad es menor que la de las demás mujeres.

Los niveles educacionales presentan la característica de dividir la población femenina en dos edades: las mujeres mayores de 40 años tienen una educación deficiente, y las de menos de 30 años un nivel francamente más alto. Considerada la población total, es notoria la diferencia entre tres generaciones. Los viejos (considerados como abuelos) y los jóvenes (en edad escolar), representan una situación de cambio y una gran distancia ideacional.

Actualmente es notorio el esfuerzo que hacen los padres para que sus hijos aprendan alguna profesión, y como necesidad manifiesta aparece la idea de que los hijos consigan por su preparación educacional una superación del nivel de los padres. Una característica de la situación actual es que las posibilidades de trabajo no hogareño se han acrecentado durante los últimos años, y son más las mujeres que ejercen un doble oficio.

Dentro del grupo socio-profesional obrero, el número de mujeres que trabajan es francamente reducido; económicamente son familias con mayores necesidades que las otras y el sueldo del esposo es muy bajo; en estos casos si la mujer no trabaja no es tanto por deseo de no hacerlo sino por las dificultades originadas en la deficiencia de su preparación profesional. La falta de capacitación dentro de este grupo le permite a la mujer ocu- 
parse únicamente en ciertos oficios muy poco remunerados, en tal forma que no alcanza este sobresueldo a compensar las dificultades que supone dejar la casa y los hijos, y aun tener que tomar otras personas que cuiden de los quehaceres de la casa. El oficio más común consiste en lavar ropa ajena en la misma casa; éste es hoy por hoy el único que les permite atender a la vez las ocupaciones del hogar.

Es interesante anotar que entre ciertas familias del grupo obrero es la segunda generación la que produce el salto hacia una vida profesional de horario completo; así, cuatro de las maestras del pueblo son hijas de familias obreras, y corresponden a esta ideación de superación que hemos señalado. No es sólo la importancia originada en una más alta remuneración económica, sino que influye sin lugar a dudas la obtención de un "status" social mucho más elevado como consecuencia de su preparación profesional.

Dentro del grupo de las familias de empleados hallamos un número de mujeres cuya preparación profesional es más calificada, perciben sueldos más altos y disponen de un mayor número de posibilidades de trabajo. Para estas amas de hogar la actitud respecto al trabajo es distinta; aun cuando el aspecto de un mayor ingreso económico familiar es importante, lo que en realidad decide los intereses de la mujer hacia la aceptación del trabajo profesional es la consideración de que ello le permite mantener una actitud más libre y a la vez vivir dentro de un "status" más elevado. La mayor parte de las mujeres de este grupo puede pagar a otra persona para que realice gran parte de los trabajos domésticos y aun aprovechar horas de vida en el hogar como descanso.

El grupo que hemos catalogado como gentes con comercio propio, puede considerarse menos homogéneo que los demás; en realidad debería ser dividido en tres, partiendo de la importancia del negocio y del valor que éste tiene como base de ingresos económicos familiares. Un primer grupo correspondería a las familias que disponen de un negocio cuyos ingresos son suficientemente altos para que no sea necesario considerar el trabajo extra como medio de aumentar los ingresos.

El segundo conjunto estaría formado por un grupo en que la mujer en forma asociada comparte la atención del negocio con su esposo, y a la vez se considera que éste proporciona sufi- 
cientes ingresos familiares para cubrir las necesidades del hogar. Estos dos grupos suelen tener personas que ayudan en el trabajo doméstico; disponen por tanto de servicios y de posibilidades económicas para pagarlo.

El tercer conjunto está representado por familias cuyo esposo tiene un pequeño negocio poco remunerativo y en el cual la mujer se halla en una situación similar a las del grupo obrero. De nuevo aquí hallamos un conjunto de mujeres con poca o ninguna preparación para poder ejercer profesiones remunerativas y generalmente resulta más económico para ellas dedicarse a la atención de los trabajos domésticos, ya que en cualquier otra ocupación no obtendría lo suficiente para poder pagar por la ayuda que necesitaría recibir para atender la vida familiar.

Otro conjunto está representado por los núcleos familiares donde no existe el esposo; se trata o bien de madres solteras o de mujeres con hijos, separadas de su esposo, o de viudas. En los tres casos, la mujer es quien ejerce la posición de jefe de familia, pero el factor edad interviene también y vemos que cuando se trata de mujeres cuyos hijos tienen edad para poder trabajar, reciben ayuda económica de ellos y organizan un tipo especial de familia más extenso. Cuando se trata de mujeres jóvenes separadas de su esposo o calificadas como madres solteras, la dependencia se establece más sobre los familiares por línea materna.

Dentro de este grupo hallamos mujeres que tienen un pequeño negocio y mujeres que ejercen un oficio doméstico, preferentemente modistería. Generalmente se han dedicado a la profesión después de aprenderla por procedimientos muy autodidactos. Es en este grupo donde la preocupación por mejorar la educación profesional de los hijos aparece más notoria; así, en el caso de mujeres con hijas mayores, encontramos que las hijas ocupan lugares profesionales calificados, desde la enfermería a trabajos de oficina. Posiblemente presenta el carácter de familia más unida y el apoyo que recibe la madre es notoriamente más alto que en los demás grupos.

Como demuestran los porcentajes establecidos, la relación entre la categoría socio-profesional del esposo y el trabajo por fuera del hogar de la mujer, tienen una ínfima correlación. Agreguemos que en algunos casos grupos de mujeres sin preparación profesional alguna, ayudan dedicándose a pequeños ne- 
gocios de tiendas o ventas, que en ocasiones no son de tiempo completo y se reducen a días festivos, cuando la afluencia de público de Barranquilla representa una más alta clientela potencial. En todos los casos hemos podido confirmar que no es sólo el factor económico el que decide la escogencia del trabajo profesional y que se considera posiblemente más importante el "status" social que se deriva del ejercicio de la profesión, sin olvidar que una mejor situación económica representa sin duda una posibilidad de cambio vertical de "status".

La relación entre el número de hijos, la categoría socioprofesional del esposo, y el trabajo femenino, no permiten llegar a una formulación única y concluyente. Tal vez lo único que puede asegurarse es que la edad de los hijos exige atención diferente por parte de la madre y que el número de ellos afecta también la disponibilidad de horas para trabajos extras; posiblemente cuando los ingresos que pueden obtenerse no compensan a las personas a quienes debe pagarse para atender a los niños pequeños, la mujer no toma trabajos por fuera de los del hogar. Cuando hay la posibilidad de que algunas de las hijas atiendan al cuidado de sus hermanos pequeños, o bien cuando algún familiar puede reemplazar a la madre, vemos aparecer, especialmente entre el grupo de familias obreras, este tipo de trabajo suplementario como el lavado de la ropa para otras gentes.

Horario de trabajo profesional y doméstico.

Debemos anotar que la duración del trabajo profesional para la mujer es realmente más importante que para el hombre, ya que hemos señalado que es ella quien condiciona la armonía de vida familiar; así, las mujeres, especialmente cuando sus hijos son de corta edad, ven recargada su vida diaria por el doble trabajo casero y profesional; era por lo tanto importante conocer en qué condiciones actúan estas situaciones. El tipo de trabajo de una empleada es mucho más regular y fijo; generalmente las horas que dedica a él son menores, si bien son casi equivalentes a las que dedica al trabajo el esposo. Ciertas profesiones, como la de costurera, no permiten establecer un número fijo de horas, ya que dependen de la demanda de su clientela, generalmente irregular y temporal; el hecho de que en épocas precisas del año, correspondiendo a fiestas tradicionales como 
Navidad, Fiesta del Mar, etc., asociadas a la costumbre de que la gente estrena ropa, producen la alternancia del trabajo de modistería, que en ocasiones durante semanas es de pedido nulo, mientras que al anticiparse las fiestas exige de estas mujeres un trabajo hasta muy altas horas de la noche.

Para las mujeres que se dedican a trabajos domésticos fuera de su casa, se presentan dos formas: la que se conoce con el nombre de trabajo por días, cuya ocupación es de 8 a 10 horas diarias, y el considerado como un tipo de trabajo de emergencia esporádico, al que se dedican preferentemente las mujeres solteras y al que sólo recurren en situaciones difíciles las esposas, como en el caso de un desempleo prolongado del jefe del hogar. Durante estos períodos, la mujer consigue que el hogar sea atendido por alguna de sus hijas mayores o bien por alguna pariente suya.

El factor distancia al trabajo no puede considerarse influyente; la población, por su tamaño, permite que se recorran a pie los trayectos entre una y otra casa. Dentro de la categoría socio-profesional de gentes con comercio propio, lo más común es que el domicilio del hogar coincida con el del negocio o que no esté tan alejado como para que a la persona que atiende el negocio le sea difícil trasladarse rápidamente varias veces al día hasta su casa. Para las mujeres de este grupo, hallamos el promedio más alto de horas de trabajo, que llega a 64 horas por semana, mientras que la ausencia diaria de las madres de familia que trabajan como empleadas, nunca es mayor de 8 a 8 y media horas. El caso de las maestras se divide entre un grupo que trabaja en jornada continua de 5 a 6 horas, considerado también como trabajo de mediodía, y, el grupo que trabaja 8 horas diarias.

El trabajo femenino generalmente está organizado en tal forma que la mujer regrese al hogar antes que el jefe de familia.

Cuando hemos hablado del tiempo de residencia en el hogar por parte del jefe de familia, tuvimos ocasión de anotar que la ayuda prestada en quehaceres domésticos es prácticamente nula. En principio el hombre considera que no le corresponde a su "status" masculino atender problemas caseros; en cambio, la ayuda que recibe la madre por parte de los niños es muchísimo mayor, atendiendo éstos casi cualquiera de los quehaceres domésticos por indicación o solicitud de la madre. 
Entre las mujeres cuyo horario de residencia en el hogar se reduce por un trabajo profesional, hallamos un porcentaje de $48 \%$, que obtienen la compensación en base al trabajo de un servicio remunerado.

Por otra parte, el promedio de ausencia cuotidiana de las mujeres que trabajan por fuera, representa 4 horas por día.

Si para el hombre el regreso al hogar es sentido como una liberación de las obligaciones de trabajo y puede dedicar este tiempo de acuerdo con sus deseos, para la mujer la situación es completamente diferente. Al regresar a la casa halla un número de tareas urgentes, como el arreglo, la cocina, el cuidado de los niños, lavado de ropa, planchado, etc., que se traducen realmente en un trabajo diario más pesado y una media horaria de 27 horas, 36 minutos por semana de trabajo fuera del hogar, además de las 39 horas, 24 minutos del promedio semanal de trabajo doméstico.

El hecho de que la mujer acostumbre a levantarse más temprano a fin de preparar desayuno, atención de los niños, salidas hacia el colegio, etc., y aun realizar parte del trabajo doméstico antes de ir hacia su segunda profesión, y de que estas mismas mujeres vayan a dormir más tarde, supone un factor decisivo para la comprensión de la estructura familiar y de los sistemas de vida de la comunidad. Las mujeres se levantan media hora antes que los hombres, y se acuestan un cuarto de hora más tarde que ellos.

En el análisis-horario no ha sido posible establecer un valor exacto para los momentos de descanso; generalmente cortos y entendidos como interrupción del trabajo, es un factor subjetivo personal y varía desde actitudes que socialmente son consideradas como de indolencia, "esta mujer descansa mucho", hasta actitudes como las de considerar que determinada persona "no tiene tiempo de parar".

Tiempo de reposo y motivos de fatiga.

Las amas de casa reconocen que disponen siempre durante el día de algunos momentos de descanso; en realidad nos parece que son superiores a los que ellas mismas evalúan, ya que es común observar que el pretexto de la llegada de una persona o del paso de una vecina es suficiente para que el trabajo se de- 
tenga y se dedique en ocasiones un buen tiempo a la conversación. Solamente hemos hallado una mujer que afirma que "no tiene tiempo para nada". Ciertas tareas domésticas se cumplen en ocasiones dentro de situaciones que representan para la persona que está trabajando una semi-recreación; así sucede siempre que la familia dispone de un aparato de radio, y se considera menos pesado el trabajo si puede compartirse con la música. Ya hemos señalado la gran preferencia por las novelas radiales; existe una especie de obsesión en no perder un solo episodio y la fascinación que produce es del orden de detener el trabajo que se está realizando; así es también frecuente que aquellas personas que por su situación económica no tienen posibilidad de disponer de un radio a domicilio, detengan su trabajo y vayan a la casa del vecino para sentarse y atender el relato radial; igualmente hemos podido anotar la suspensión del trabajo, aun sin salir de la casa y no disponiéndose de radio, a fin de poder escuchar la emisión que cualquiera de los vecinos está sintonizando a todo volumen, hasta el punto de que en muchas ocasiones se escucha un radio a una cuadra de distancia.

Otro elemento que sigue en importancia es la lectura, que si bien depende mucho de la educación individual, representa siempre un tiempo de dedicación. Lo más común es la lectura de revistas y novelas de bajo precio, que la gente clasifica como novelas de amor romántico; el entusiasmo llega al punto de que repetidamente hemos oído la afirmación de que "hoy debo recuperar el trabajo que no pude hacer, ya que tenía que terminar una novela que me había sido prestada". El intercambio de novelas constituye un verdadero motivo de relación social, y es precisamente entre las mujeres del grupo obrero que menos disponen de aparatos de radio, donde en más ocasiones se utiliza la lectura como sistema de recreación y de descanso.

El grupo de maestras y empleadas, en función de su propia preparación profesional, realizan una selección de la literatura y tienen preferencia por revistas como Life y Selecciones o una literatura más calificada, y no es raro encontrar la preocupación por temas de educación y aun sociológicos.

Nuestra encuesta pudo establecer que quienes más se quejan del trabajo son las mujeres del grupo socio-económico obrero; consideran grande la fatiga que produce el trabajo en el hogar, el cuidado de los hijos, y, es común la afirmación de que casi no 
se tiene tiempo para descanso; no obstante, la observación real de su horario hecha por nosotros, permite afirmar que descansan durante mucho más tiempo del que ellas mismas creen, si bien en forma de intervalos y en base a aprovechar todo pretexto que permita detener por un momento su tarea. Naturalmente no manifiestan el deseo de tener un número mayor de ocupaciones y consideran como ideal el que mejore el sueldo del esposo, para vivir más confortablemente. En cambio, entre las mujeres de los grupos cuya posibilidad económica y cuya situación social es superior, ya sea ello por la profesión del esposo o por la propia preparación de la mujer, se manifiesta vivamente el deseo de poder vivir algún día en una ciudad y trabajar profesionalmente; esto es mucho más notorio entre mujeres que durante su vida soltera se dedicaron a una determinada profesión que abandonaron al casarse.

Al investigar las causas de fatiga, casi siempre hallamos una misma forma de expresarlas, que puede reducirse a lo siguiente: la fatiga se debe a la incomodidad de la vivienda; no es fácil lavar la ropa; es complicado lavar la vajilla; arreglar dos o tres piezas para un promedio de 8 a 10 personas significa tener que mover muebles, barrer en condiciones no confortables, etc.; así vemos que tan pronto la familia mejora en posibilidades económicas, trata de hacer reformas y ampliaciones en las casas, conseguir muebles más cómodos y aun tratar de obtener lo que se considera un ideal y que sólo poseen las clases sociales favorecidas: una nevera.

Sobre este núcleo de incomodidad se halla la justificación de que las mujeres que trabajan solamente en oficios domésticos sientan más cansancio, y casi una envidia para aquellas que pueden trabajar fuera de su casa, aun cuando en realidad su trabajo sea más pesado, pero pueden así rehuír gran parte de trabajo hogareño, que se confía a una persona de servicio.

Razones para trabajar y aspiraciones.

La justificación del porqué trabajan las mujeres nos dio exactamente un $50 \%$ expresada en términos de necesidades económicas, que en esencia pueden reducirse a alcanzar un presupuesto familiar para la alimentación, educación de los hijos, vestido y un reducido número de recreaciones como la asistencia 
un día por semana al cine o el viaje un par de veces por mes a Barranquilla. Un 28,5\%, lo justifican como necesidad económica y como prestigio social, y un $8 \%$ porque el trabajo les permite una mayor libertad y unos ingresos disponibles casi en términos personales. Entre el grupo de las que no trabajan por fuera del hogar, la mayoría lo justifica como el que esto no tiene interés y no mejoraría su situación económica, ya que lo que ganaría no equivaldría a lo que deberían pagar a la persona que se ocupase de la atención del hogar que ahora realizan ellas. No obstante, opinamos que se trata también de una imposibilida material de conseguir un trabajo, por incapacidad personal.

Debe establecerse una excepción para lo que llamaríamos trabajo esporádico. Se trata, en realidad, de casos en que la mujer trabaja como consecuencia de la falta de empleo del esposo, cuando el paro obrero es prolongado y el jefe de familia sólo consigue recursos ocasionales. Hemos podido observar numerosas familias en que los ingresos del padre son tan reducidos que afectan el régimen alimenticio familiar hasta el punto de que hay sólo por día una comida relativamente completa, ya que por la mañana y por la noche se reduce la alimentación al consumo de agua de panela o café. No obstante, en algunas de estas ocasiones, la mujer tampoco recurre a trabajos extras, alegando que el quehacer en el hogar no le da tiempo para ello.

A continuación analizamos los apartes del ritmo de vida diario para las 28 familias estudiadas.

Horas en trabajo doméstico femenino por semana.

De los casos analizados, hallamos un total de 1.069 horas dedicadas a trabajo doméstico, sobre las 4.536 horas semanales (24 horas diarias para 27 personas), lo que significa que un $23,5 \%$ del tiempo total se destina a ocupaciones caseras.

Los promedios semanales de trabajo femenino doméstico, discriminados por categorías sociales del esposo, se ordenan en la forma siguiente: para la familia de pescadores, 56 horas; de los obreros, 52 horas; de los intermediarios, 44 horas; de los sin empleo, 42 horas; empleados, 41 horas; sin esposo, 37 horas, 30 minutos, y con comercio propio, 18 horas, 54 minutos. Han sido ordenados en forma decreciente, a fin de establecer los valores relativos y hallar el promedio total de horas de trabajo feme- 
nino doméstico para todos los grupos, el cual nos da la cifra de 39 horas, 24 minutos.

Clasificadas las amas de casa según su trabajo y horas semanales dedicadas, hallamos una ocupación decreciente así: intermediarias, 51 horas, 30 minutos; hogar y trabajo en la casa, 51 horas, 18 minutos; hogar sólo, 49 horas, 42 minutos; mujeres jefes de hogar que mantienen la familia, 36 horas, 12 minutos; mujeres con comercio propio, 28 horas, 30 minutos, y empleadas, 24 horas.

Horas de trabajo femenino no doméstico.

El total promedio de los 28 casos analizados da por semana la cifra de 27 horas, 30 minutos. Pueden resumirse por categorías femeninas en lo siguiente: el máximo corresponde a mujeres con comercio propio, con un promedio de 65 horas; siguen las mujeres jefes de familia, con 52 horas; las intermediarias, con 50 horas, 30 minutos; las empleadas, con 24 horas, y las mujeres dedicadas al hogar y que trabajan en la casa, con 13 horas, 42 minutos.

Si consideramos este tiempo dedicado al trabajo femenino no doméstico según la categoría socio-profesional del esposo, hallamos lo siguiente: las mujeres cuyo esposo tiene comercio propio que ellas comparten, trabajan 39 horas, 18 minutos por semana; siguen las mujeres de los empleados, con 27 horas, $24 \mathrm{mi}$ nutos; luégo mujeres de obreros, con 27 horas, 6 minutos; mujeres jefes de hogar sin esposo, con 27 horas, y, finalmente, las mujeres de los intermediarios, con 16 horas, 30 minutos.

El promedio total para las 28 familias encuestadas es de 27 horas, 36 minutos semanales para el trabajo no doméstico de la mujer.

Ingresos por trabajo femenino en relación con el salario del esposo.

Del análisis total para la relación entre los ingresos del jefe de familia, más el aporte del ama de la casa, hallamos los promedios siguientes: familias obreras, jefe del hogar, $\$ 177.00$; promedio de la esposa, $\$ 50.00$; familias de empleados, ingresos 
mensuales del jefe del hogar, $\$ 588.35$, aporte de la esposa, $\$ 347.50$; para comerciantes, ingreso del jefe del hogar, $\$ 1.531 .50$, ingresos por la esposa, $\$ 841.25$; pescadores, ingreso del jefe de familia, $\$ 600.00$, aporte de la esposa, $\$ 50.00$; jefe del hogar que maneja una industria casera, ingresos, $\$ 200.00$, aporte de la esposa, $\$ 167.00$.

Si analizamos ahora desde el punto de vista de estructura familiar, introduciendo todas las categorías socio-profesionales masculinas con relación a la situación de la mujer, hallamos lo siguiente: para las mujeres dedicadas al hogar, además de un negocio en la propia casa, el ingreso del esposo corresponde a $\$ 609.10$ y el aporte femenino a $\$ 170.00$; las mujeres empleadas perciben como ingreso de sus esposos, $\$ 826.65$, y ellas aportan $\$ 410.00$; para el caso de mujeres que mantienen el hogar, el promedio de ingresos es de $\$ 390.00$; para mujeres con la actividad de intermediarias el ingreso por el esposo da un promedio de $\$ 175.00$, mientras que ellas aportan $\$ 168.50$.

Analizados como casos particulares los ingresos más bajos por categorías socio-profesionales, serían los siguientes: para los obreros, \$ 75.00; para los comerciantes, \$ 120.00 ; para los intermediarios, $\$ 150.00$; para los empleados, $\$ 180.00$, y para los pescadores, $\$ 600.00$.

En las mismas categorías los ingresos máximos serían: intermediarios, $\$ 200.00$; obreros, $\$ 270.00$; empleados, $\$ 1.500 .00$; comercio propio, $\$ 5.500 .00$.

La situación de ingresos femeninos para las mujeres que además de cuidar el hogar trabajan o atienden negocio en la casa, sería de un mínimo de $\$ 30.00$ mensuales a $\$ 750.00$ mensuales; los ingresos de las empleadas oscilan entre $\$ 300.00 \mathrm{y}$ $\$ 700.00$ mensuales. Para las mujeres jefes de familia sin esposo que mantienen el hogar, oscila entre $\$ 60.00$ y $\$ 120.00$ por mes, y para las mujeres clasificadas como intermediarias, la variación es de $\$ 167.00$, mínimo, y $\$ 170.00$, máximo.

Ingreso familiar, distribuído por categorías socio-profesionales femeninas.

Los promedios evaluados dan las siguientes cifras para las diferentes formas de ingreso: 
Mujeres que trabajan en su casa para otras personas:

Mensuales

Por trabajo de la mujer. $\ldots \ldots \ldots \ldots \ldots$

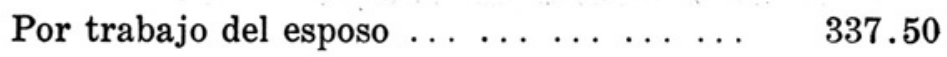

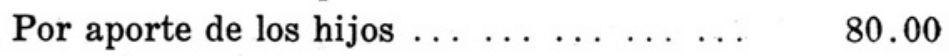

Mujeres empleadas:

Por trabajo de la mujer. . . . . . . . . . . $\quad 512.50$

Por trabajo del esposo . . . . . . . . . 826.65

Por aporte de los hijos . . . . . . . . . . . $\quad 0.00$

Mujeres intermediarias:

Por trabajo de la mujer. . . . . . . . . . $\quad 168.00$

Por trabajo del esposo $\ldots \ldots \ldots \ldots \ldots \ldots$

Por aporte de los hijos $\ldots \ldots \ldots \ldots 0$

Mujeres con comercio propio:

Por trabajo de la mujer . . . . . . . . . . 484.45

Por trabajo del esposo $\ldots \ldots \ldots \ldots \ldots$

Por aporte de los hijos $\ldots \ldots \ldots \ldots$

Los ingresos mayores corresponden a la familia clasificada como rentista, que representa un caso especial, el cual si se suma al grupo de mujeres que sólo atienden el hogar, nos daría una cifra falseada; así este caso se considera aparte, ya que representa la suma de $\$ 3.600 .00$ mensuales para esta familia.

Con referencia a las mujeres que sólo atienden el hogar, tenemos :

Mensuales

Por trabajo de la mujer. . . . . . . . . . . . . $\$ \$ \quad 0.00$

Por trabajo del esposo $\ldots \ldots \ldots \ldots \ldots \ldots$

Por aporte de los hijos $\ldots \ldots \ldots \ldots \ldots$ 
Los promedios totales de ingresos serían los siguientes:

Por ingreso mensual de la mujer . . . . . . . \$ $\quad 551.90$

Por ingreso mensual del esposo . . . . . . . . . . . $\quad 901.85$

Por aporte mensual de los hijos . . . . . . . $\quad 407.50$

Total del ingreso familiar promedio $\ldots \ldots \$ 1.125 .05$

Discriminado en categorías socio-profesionales femeninas, tendríamos los promedios siguientes:

Para familias en que la mujer trabaja en el hogar para otras

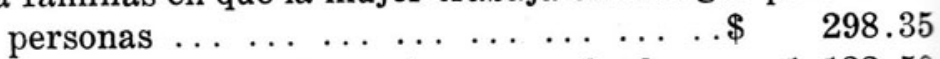

Para familias en que la mujer es empleada ... 1.132 .50

Para familias en que la mujer es intermediaria 343.00

Para familias con negocio propio en el que par-

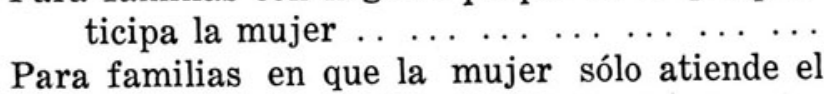
1.242 .25 hogar (con la indicación que reúne las clases económicas más o menos pudientes) $\ldots \quad 1.495 .00$

Personas económicamente dependientes.

Estos valores constituyen en realidad un anexo al cuadro de ingresos familiares y han sido distribuídas por actividades socio-profesionales de la mujer.

Los promedios se establecen así:

Para familias en que la mujer trabaja en el hogar para personas extrañas a la familia, hay 26 personas dependientes, de las cuales 2 son hijos, con el esposo, y 2 clasificados como hijos naturales, adoptivos y familiares a cargo.

Para familias en que el ama del hogar trabaja como empleada, el promedio de personas dependientes es de 4,5, del cual 2,6 son hijos con el esposo.

Para familias en que la mujer se clasifica como intermediaria, 4 son personas dependientes y corresponden a 4 hijos con el esposo.

Para las familias en que la mujer tiene comercio propia 2,7 son personas dependientes, y su total corresponde en prow 
medio a 3 hijos con el esposo y dos a hijos naturales, adoptivos o personas a cargo.

Para familias en que la mujer sólo se ocupa del trabajo doméstico el total de personas dependientes es de 5,5, correspondiendo 5,3 a los hijos con el esposo.

Un promedio totalizado para las familias estudiadas daría 3,9 como personas dependientes, un 3,8 para hijos con el esposo, y un total de 2,4 para distribuír entre todas las familias y correspondiendo a hijos naturales, adoptivos, $y$ familiares por parentesco o extraños a cargo de la familia.

Ayuda recibida en el trabajo doméstico.

En los 28 casos estudiados, la mujer recibe ayuda en sus trabajos en el siguiente orden de importancia:

En el lavado, plancha y remiendo de ropas . . . . . 14

En la limpieza de la casa . . . . . . . . . . . . . . . . 12

En la preparación de la comida $\ldots \ldots \ldots \ldots \ldots$. $\ldots \ldots \ldots$

En mercado, compras y encargos . . . . . . . . . . 10

En la preparación de desayunos ............. $\ldots 10$

En la atención y cuidado de los niños . . . . . . . . 7

Para estas 28 familias el ama de casa no recibe ayuda y atiende todo el trabajo doméstico en 7 casos.

Por categorías socio-profesionales de la familia, quienes reciben mayor ayuda son las mujeres con comercio propio y empleadas; siguen las familias obreras, las mujeres jefe de familia y los pescadores, para terminar con las familias sin empleo en que la mujer sólo cuenta con una pequeña ayuda de los hijos e hijas mayores si los hay, que atienden pequeños quehaceres.

Promedio de horas destinadas a recreación por semana.

El concepto recreación queda reducido en el grupo estudiado de 28 familias al tiempo dedicado a descanso, conversación, visitas y compras, audición de radio-novelas, lecturas, espectáculos, paseos y juegos de salón.

Relacionados los elementos anteriores con las diferentes categorías de amas de casa, hallamos que el mayor tiempo disponible para recreación se dedica a descanso y conversación, con 
valores semanales de 109 horas, 5 minutos, y 108 horas, 5 minutos, respectivamente, lo que significa que de las 381 horas, 35 minutos del total semanal, 217 horas, 10 minutos, se dedican a las dos actividades anotadas, y sólo quedan 164 horas, $45 \mathrm{mi}$ nutos para los demás.

En realidad, si añadimos el tiempo de visitas y compras, que es de conversación principalmente, y que ocupa 53 horas, 20 minutos; hallamos que la mayoría del tiempo se dedica al contacto verbal con otras personas, con un valor semanal de 105 horas, 25 minutos.

Hallamos también que, con excepción del ama del hogar clasificada como rentista, quienes disponen de más tiempo para recreación son precisamente las mujeres que además de atender la casa, trabajan para otras personas, ya que disponen de 67 horas, 55 minutos. Esto que podría parecer paradójico no lo es si se considera que estas personas disponen de servicio para su ocupación doméstica.

Empleadas e intermediarias, gastan, respectivamente, 53 horas, 45 minutos, y 51 horas, 30 minutos, mientras que quienes sólo cuidan de su hogar y quienes atienden un comercio propio disponen, respectivamente, de 49 horas, 35 minutos, y 45 horas, 25 minutos por semana.

Podemos también deducir los datos siguientes: el mayor número de horas dedicadas a conversación, corresponden al ama de casa clasificada como rentista, y el menor a las personas empleadas variando entre 42 horas y 10 horas, 30 minutos por semana. No obstante, debemos eliminar del análisis la persona clasificada como rentista, que constituye realmente una forma excepcional, y entonces hallamos que las diferencias oscilan entre las 16 horas, 5 minutos, que corresponden a quienes sólo cuidan del hogar, y 10 horas, 30 minutos, para el grupo de empleadas.

Sigue en importancia el número de horas clasificadas como descanso, que oscilan (no teniendo en cuenta la rentista), entre el máximo de 17 horas, 30 minutos, que corresponde a empleadas, y 10 horas, 45 minutos, que corresponde a mujeres con negocio propio.

El análisis del cuadro número 3, que presentamos a continuación, permite establecer el promedio de horas semanales dedicadas a recreación. 


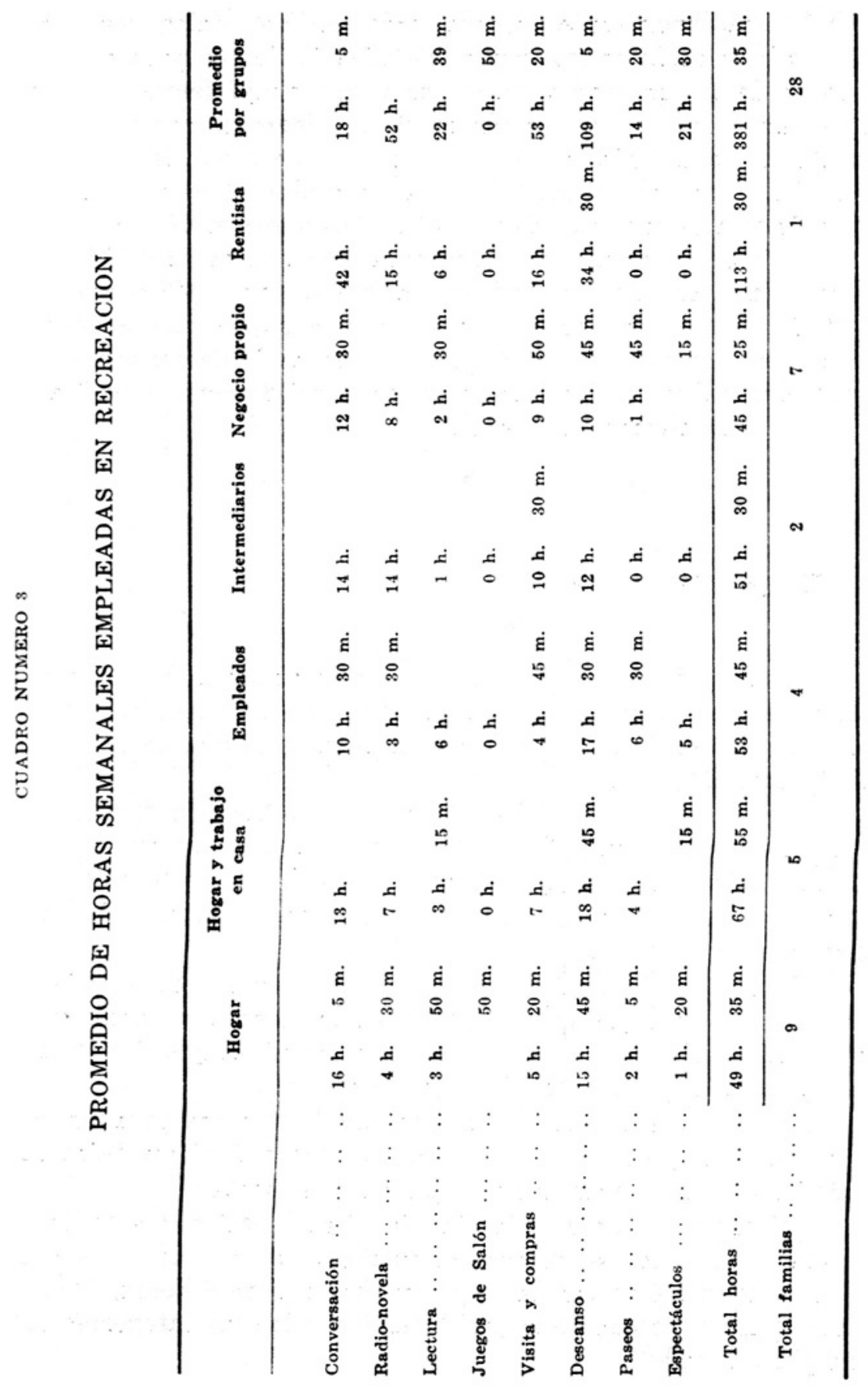


Lo más importante de considerar son los totales comparativos y la relación de las disponibilidades de tiempo para recreación desde el punto de vista del tipo de trabajo femenino. Por otra parte, como la recreación puede considerarse como un elemento en donde más incide la posibilidad personal de escogencia, tiene una importancia notoria averiguar el valor relativo de cada una de las actividades destinadas a recreación.

El total de horas semanales para 28 casos es de 4.704 (24 horas día); de éstas se destinan a recreación 1.546 o sea un $33 \%$ del tiempo. Este dato es importante dado que estas personas creen sinceramente que no disponen de horas de descanso y esta impresión subjetiva les hace afirmar repetidamente que "casi nunca tienen tiempo para nada".

Tiempo destinado al sueño.

El promedio total de horas que corresponde a las amas de hogar estudiadas y que suma tanto las horas de sueño nocturno como las horas dedicadas a la siesta durante el día, da la cifra de 8 horas, 54 minutos.

Los promedios parciales en base a la ocupación femenina, oscilan entre 10 horas, 45 minutos, como máximo, que corresponde a las intermediarias; y 7 horas, 45 minutos a la categoría con comercio propio, cifras éstas para el total de horas, incluídas las siestas durante el día.

Para el sueño nocturno el promedio menor corresponde a mujeres que trabajan en el hogar y tienen además comercio propio, con un total de 7 horas, 20 minutos, mientras que el máximo se da entre empleadas con 8 horas, 48 minutos.

La siesta oscila entre el máximo de 60 minutos para las intermediarias, y el mínimo que corresponde a mujeres jefes de familia que no dedican ningún tiempo a la siesta.

El promedio para todas las familias investigadas es de 8 horas, 25 minutos, destinados al sueño, y 35 minutos a siesta diurna, lo que a su vez da un promedio total de 8 horas, $34 \mathrm{mi}-$ nutos para las amas de hogar, incluídas todas las categorías socio-profesionales. 
Al relacionar el tipo de actividades femeninas en el hogar y fuera de él, con respecto a la categoría socio-profesional del esposo, hallamos que para el grupo obrero, el $52 \%$ sólo se ocupa en labores domésticas y el resto obtiene ingresos extras por lavado de ropa, venta o labor de intermediarias y un caso de cartomancia.

Discriminados los grupos, tenemos que entre los empleados sólo el $20 \%$ de las mujeres se ocupan del hogar y el resto trabaja como maestras o empleadas, y en un caso es la mujer quien mantiene económicamente su familia.

Para las categorías socio-profesionales de intermediarios y comercio propio, la mitad de las mujeres sólo se ocupa del hogar y la otra mitad trabaja en otros oficios además de los de la casa.

Quedan familias sin esposo, donde hemos hallado cinco casos en que la mujer sólo se ocupa del hogar, uno en que además trabaja como modista y otro como empleada. Este grupo representa el $8,5 \%$ de los hogares estudiados, y tiene gran importancia para la evaluación de la estructura social familiar.

Razones aducidas para trabajar.

El $50 \%$ de las mujeres consideran su trabajo extra-hogareño como necesario para equilibrar el presupuesto familiar; el $10,4 \%$ son madres solteras y deben atender los ingresos familiares; un $7,2 \%$ desean trabajar para obtener con ello una mayor libertad; un $28,4 \%$ consideran que su trabajo significa un mayor "status" y prestigio social, y un 3,5\% debe trabajar por abandono total del esposo.

Ideaciones respecto al trabajo.

Para un 21,5\% es considerado como beneficioso para la mujer; un $28,4 \%$ creen que es una obligación insuperable; un $3,5 \%$ lo formulan como deseable; un $32,1 \%$ como beneficioso y obligatorio, y un $14,3 \%$ como beneficioso y deseable. 
Por otra parte, el trabajo femenino se distribuye así: el $62,2 \%$ constituyen familias nucleares matrimoniales; $8,3 \%$ no están casadas; un $12,5 \%$ el esposo no vive en el hogar, $12,5 \%$ corresponde a madres solteras. Entre estas mujeres sus profesiones se distribuyen así: cartomancia, $8,3 \%^{1}$; costura y modistería, $12,5 \%$; lavado de ropa esporádico, $4,2 \%$; intermediarias, $8,3 \%$; maestras, $20,9 \%$; ventas en quioscos (comidas, bebidas), $12,5 \%$; dueñas de almacenes, $16,7 \%$; secretarias, $4,2 \%$; sin trabajo (rentistas), 4,2\% ; fabricación casera de dulces, conservas, etc, $4,2 \%$; enfermeras, $4,2 \%$.

Trabajo pre-matrimonial.

En cuanto al trabajo femenino referido a ocupaciones prematrimoniales, hallamos que de 28 familias investigadas, sólo 2 habían trabajado antes de casarse, una como niñera y otra como maestra.

Hijos en el hogar.

Con respecto al número de hijos sobre 28 familias, hallamos un total de 103 hijos viviendo en el hogar, o sea un promedio familiar de 4,64 hijos por familia; quedan, naturalmente, por fuera, aquellos hijos que por su edad, estudios, matrimonio, etc., no residen con sus padres.

Por otra parte, hallamos la constitución familiar según el número de hijos con el esposo propio con un promedio de 5,3 más un 0,5 de hijos de otros padres, que nos eleva el total familiar a 5,8 hijos (prácticamente 6) como promedio.

El Gráfico número 2 resume cinco casos que representan los horarios más típicos para el grupo de amas de casa según categorías socio-profesionales.

1. Esta cifra no significa que el $8,7 \%$ de la población total se dedique a la cortomancia; su porcentaje es dado por la evaluación sobre 28 casos. 
GRAFICO № 2

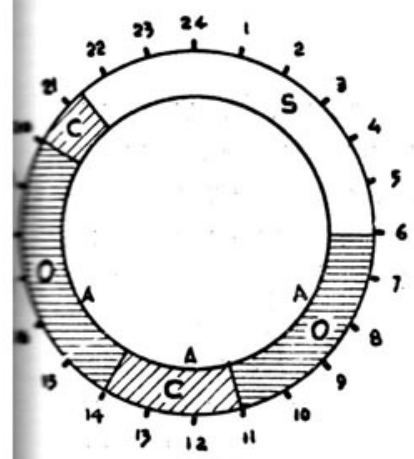

PABANO DOMESTICO Y NIÑOS

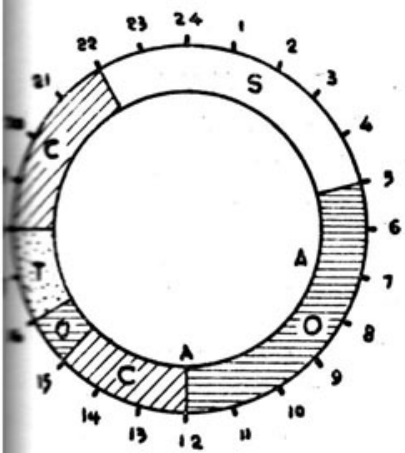

DDISTA (12)

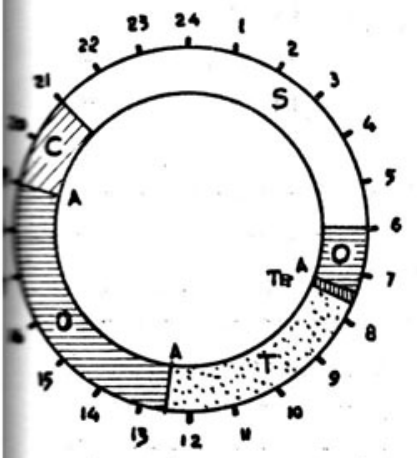

MPLEADA (25)

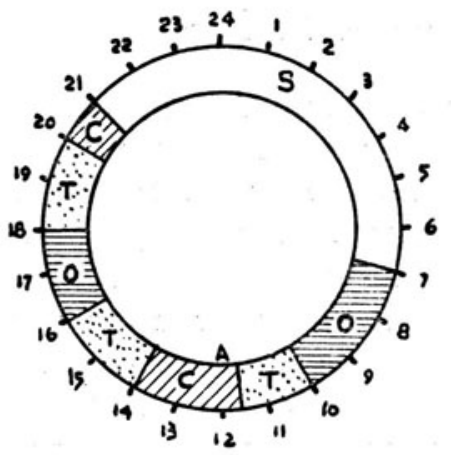

INTERMEDIARIA (II)

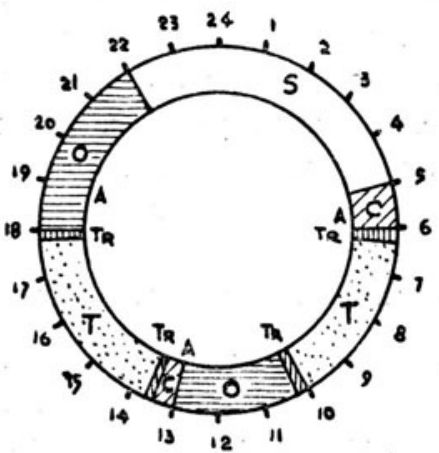

NEGOCIO PROPIO- CON EBPOSO (19)

CONVENCIONES

\begin{tabular}{|c|c|c|}
\hline & & SUEÑO \\
\hline & C* & CASA \\
\hline एIII & & TRANSPORTE \\
\hline 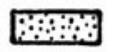 & & TRABAJO \\
\hline 曲 & & EST \\
\hline$\pi$ & & RECREACIOI \\
\hline
\end{tabular}

$A A=$ COMIDA

臂 $O$ - OFICIO DOMESTICO 


\section{CONCLUSIONES}

Familia y cambios técnicos.

Las estructuras de parentesco, así como las unidades familiares que hallamos como cimiento de las relaciones sociales en las comunidades pre-industriales, son posiblemente los elementos más afectados en los procesos de cambio técnico-económico.

En Puerto Colombia la constitución de la familia se halla frente a cambios en cuanto a amplitud y régimen de control de sus miembros en función de los tipos de trabajo. La dimensión familiar se vierte hacia unidades de parentesco más restringido, y ciertas funciones familiares entraron en declinación por cambios producidos a nivel educacional, sanitario, de protección y seguridad, etc., mientras en algunas otras manifestaciones una incontestable permanencia por el régimen de seguridad individual centrado en lo atávicamente aceptado por la comunidad. Posiblemente los mayores cambios se refieren a las relaciones entre los miembros de la familia, cada día más independientes en función de las oportunidades y horarios de trabajo.

Los cambios principales afectan a los siguientes niveles:

a) La dimensión familiar; parece manifestarse una tendencia hacia la familia nuclear a expensas de la familia extensa, que por mucho tiempo había constituído la unidad sociológica, jurídica y económica. En este cambio las mayores dificultades surgen del ajuste mediocre en las relaciones entre los esposos por la reducción del cuadro familiar. No obstante, la relaciones de parentesco extenso continúan aún con la separación domiciliaria y se mantienen para contribuír a la seguridad material y moral de los individuos.

b) Composición familiar; parece posible afirmar la reducción de formas polígamas, pero este proceso ni es simple (debido a unas pocas causas) ni tiene un sentido único. La tasa alta de separaciones se manifiesta como forma de "poligamia sucesiva".

c) Inestabilidad familiar; el número relativamente grande de uniones libres y de separaciones, está ligado a cambios de "status"' de la mujer, que hoy se centra sobre la mayor posibilidad de poder atender a los hijos sin la dependencia total de la ayuda paterna, como era norma en generaciones pasadas. 
d) El "status" de la esposa ha mejorado, al poder alcanzar más fácilmente niveles de trabajo remunerado. Todo parece indicar la aparición de nuevos tipos ideacionales con respecto a la familia.

La estabilidad de las uniones, así como la cualidad de las relaciones entre la madre y los niños, no depende necesariamente de la legalización de las uniones y no ha podido hallarse una relación directa entre el número de uniones libres y la estabilidad familiar, siendo numerosas las familias estables que resultaron de las uniones libres.

Nos parece, en cambio, mucho más decisivo en la dinámica familiar y de grupo el sistema organizado de la vida diaria, y consideramos que esto es justificativo del enfoque de este capítulo de nuestro estudio global.

\section{BIBLIOGRAFIA}

Chombart de Lauwe, Paul, et le groupe d'Ethnologie Sociale. 1959.-Famille et habitation. Sciences Humaines et Conceptions de l'Habitation. Centre National de la Recherche Scientifique. Paris.

Vila, Pablo. 1945.-Nueva Geografía de Colombia. Bogotá.

Esguerra O., Joaquín. 1879.-Diccionario Geográfico de los Estados Unidos de Colombia. Bogotá.

Angulo Valdés, Carlos. 1952.-El Departamento del Atlántico y sus Condiciones Físicas. Revista Geográfica. Universidad del Atlántico. Instituto de Investigación Etnológica, Vol. I, No 1. Barranquilla.

Tovar ARIzA, RAFael. 1952.-Salgar y el Ataque Marino. Revista Geográfica. Instituto de Investigación Etnológica. Universidad del Atlántico. Vol. I, No 1. Barranquilla.

Sailing Directions for East Coasts of Central America and Mexico Including North Coast of Colombia. 1939.-United States Navy Department, Hydrographie Office. Fourth Edition. 